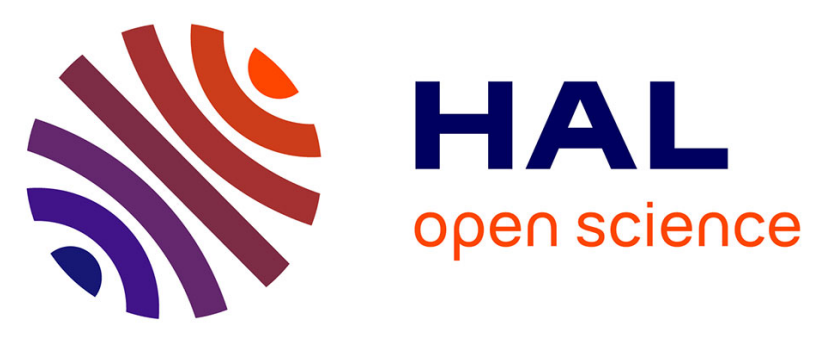

\title{
Well injectivity during CO2 storage operations in deep saline aquifers - Part 2: Numerical simulations of drying, salt deposit mechanisms and role of capillary forces
}

Laurent André, Yannick Peysson, Mohamed Azaroual

\section{- To cite this version:}

Laurent André, Yannick Peysson, Mohamed Azaroual. Well injectivity during CO2 storage operations in deep saline aquifers - Part 2: Numerical simulations of drying, salt deposit mechanisms and role of capillary forces. International Journal of Greenhouse Gas Control, 2014, 22, pp.301-312. 10.1016/j.ijggc.2013.10.030 . hal-00932777

\section{HAL Id: hal-00932777 https: / hal-brgm.archives-ouvertes.fr/hal-00932777}

Submitted on 17 Jan 2014

HAL is a multi-disciplinary open access archive for the deposit and dissemination of scientific research documents, whether they are published or not. The documents may come from teaching and research institutions in France or abroad, or from public or private research centers.
L'archive ouverte pluridisciplinaire HAL, est destinée au dépôt et à la diffusion de documents scientifiques de niveau recherche, publiés ou non, émanant des établissements d'enseignement et de recherche français ou étrangers, des laboratoires publics ou privés. 
Part 2: Numerical simulations of drying, salt deposit mechanisms and role of capillary forces 
The injection of $\mathrm{CO}_{2}$ into geological reservoirs or deep saline aquifers is being studied to control global warming by limiting greenhouse gas emissions. $\mathrm{CO}_{2}$ is captured from exhaust gases in power plants or industrial units and stored in underground geological reservoirs. Return on experience withCO $\mathrm{C}_{2}$ injection in the oil industry clearly shows that injectivity problems can be encountered due to several mechanisms including mineral dissolution/ precipitationand physical alteration due to the complete desaturation of the near-wellbore zone. This study describes numerical modelling that is able to reproduce the experimental results of drying of brine-saturated sandstone cores by gas injection in the laboratory. The evolution of water and gas saturation profiles and the precipitation of salt inside the samples are followed with injection time. Numerical results agree well with experimental observations highlighting the key role played by capillary forces during the desiccation process (see the companion paper; Peysson et al., 2013). A tentative extrapolation of experimental results from laboratory scale to the near-well field scale is proposed. This approach is of major importance because it makes it possible to determine the optimal $\mathrm{CO}_{2}$ injection flow rate according to both the intrinsic petrophysical properties of the porous medium and initial brine salinities.

Keywords: supercritical $\mathrm{CO}_{2}$, drying-out effects, coupled modelling, relative permeability. 


\section{Introduction}

Geological sequestration of $\mathrm{CO}_{2}$ in deep saline aquifers offers a promising solution for reducing net emissions of greenhouse gases into the atmosphere. Nevertheless, this emerging technology based on massive $\mathrm{CO}_{2}$ injection in saline reservoirs can cause a major disequilibrium of the physical and geochemical characteristics of the host reservoir. Recent numerical simulations indicate that the near-well zone is the area most sensitive toand impacted by the injection of supercritical $\mathrm{CO}_{2}$.Geochemical reactions (e.g., $\mathrm{CO}_{2}$ dissolution, $\mathrm{pH}$ variation of original brine, mineral dissolution/precipitation) are expected to occurmainly in this zone (Ennis-King and Paterson, 2007; Audigane et al., 2007; André et al., 2007, 2010; Huq et al., 2012). Moreover, physical phenomena (e.g., variations in temperature, pressure, gas saturation) will also generate major perturbations of the equilibriumof the host reservoir (Bielinski et al., 2008; Kopp et al., 2009; Okwen et al., 2011, Menhert and Okwen, 2012; Vilarrasa, 2012). Consequently, all of these processes might combine to enhance or alter its initial porosity and permeability and long-term well injectivity. Detailed studies need therefore to be carried out before effective gas injection in order to predict the sustainability of the system and optimize the injection phase.

Among these perturbations, the desiccation of the porous medium appears to be a major phenomenon with various positive or negative implications such as salt precipitation (Peysson et al., 2010, Ott et al., 2010a, b), modifications of the local geomechanical constraints and internal forces (Peter-Borie et al., 2011), and impacts of injected fluids on the interfacial tensions including capillary/osmotic phenomena (Leroy et al., 2010). Desiccation of porous media subjected to gas injection has been investigated at the laboratory scale on cores (Mahadevan, 2005; Mahadevan et al., 2007;Peysson, 2012) and on a chip (Kim et al., 2013). This process has also been observed $a^{2}$ the field scale during the injection of dry gas into oil and gas reservoirs (Kleinitz and Tölcke, 1982; Kleinitz et al., 2001, 2003; Vandeweijer et al., 2011). Salt deposits cause a pressure draw-down in injection wells or decrease productivity in production wells. The modelling of $\mathrm{CO}_{2}$ storage in deep saline aquifers has 
emphasized the importance of drying mechanisms on injectivity (Pruess and Muller, 2009; Giorgis et al., 2007; Hurter et al., 2007; André et al., 2007; Zeidouni et al., 2009; Alkan et al., 2010) and has led to new research efforts on that topic.

Mechanistically, the massive and continuous injection of $\mathrm{CO}_{2}$ in an initially saturated porous medium causes water displacement and evaporation. First, mobile water is pushed out by the injected supercritical $\mathrm{CO}_{2}$ according to two-phase displacement (brine - $\mathrm{CO}_{2}$ ). At the end of this phase, immobile residual water trapped in pores or distributed on grain surface as thin filmscomes in contact with the flowing dry $\mathrm{CO}_{2}$. Consequently, a continuous and extensive evaporation process leads both to the formation of a reactive drying front moving into the medium, and the precipitation of salts and possibly secondary minerals in residual brines (Mahadevan et al., 2007). This desiccation and the following salt precipitation are also highly influenced by capillary forces, which draw the brine towards the injection points (Giorgis et al., 2007).

This study investigated the consequences of near-wellbore drying-out on well injectivity through the evolution of the petrophysical properties of the porous medium. The objective was to determine the key processes controlling the drying of the porous media during the injection of dry gas, and identify the parameters needed to predict the behaviour of the salt (dissolved and solid) inside the core. Our understanding of these processes is essential for the long-term management of the evolution of gas injection into the reservoir.

The work involved both laboratory experiments and numerical modelling. The drying potential of a gas phase wasstudiedin the laboratory on sandstone plugs $(6 \mathrm{~cm}$ in length and $4.9 \mathrm{~cm}$ in diameter) (Peysson et al., 2013). These experiments were then interpreted using a numerical modelling approach coupling hydraulic, thermal and thermodynamic processes able to simulate the evolution of liquid and gas saturation in time and space. A very fine discretization of the plugs enabled us to capture the continuous evolution of water, gas and salt profiles in the porous medium and estimate the porosity and permeabilityvariations during the drying process. 
The parameters established at the centimetre scale were then used without modification in order to extrapolate the results at the near-wellbore scale and predict the impact of $\mathrm{CO}_{2}$ injection on the petrophysical properties of the host rock. A precise description of fluid (gas and water) flows inside the reservoir enabled us to identify the key processes, and, for given rock properties, the clogging risks due to salt precipitation related to the $\mathrm{CO}_{2}$ injection flow rate.

\section{EXPERIMENTAL APPROACH AT THE LABORATORY SCALE}

\subsection{Rock samples: characterization and hydraulic properties}

Vosges sandstones were selected for this study because it is a rock-type representative of the Triassic formations from Eastern part of Paris Basin (France), which were identified as potential reservoirs for $\mathrm{CO}_{2}$ storage (Sterpenich et al., 2006). Vosges sandstones, also wellknown for their homogeneity, were sampled in a quarry. It is composed of quartz (70 - $80 \%)$, microcline (10 -20\%) and about $10 \%$ of a mixture of muscovite, albite, smectite, anorthite and hematite (Sterpenich et al., 2006). Cylindrical cores $6 \mathrm{~cm}$ in length and $2.5 \mathrm{~cm}$ in diameter are prepared from the sampled block.

The hydraulic properties of Vosges Sandstones were characterized: porosity $(\Phi)$ and permeability $\left(\mathrm{K}_{0}\right)$ were $21.8 \%$ and $74 \mathrm{mD}$, respectively. A high pressure mercury injection was used to measure the pore throat distribution (Peysson, 2012). This injection also allowed determining the gas-water capillary pressure curve (Fig. 1).

For next numerical simulations, a standard Corey model (Corey, 1954) was used to represent relative permeability curves of both the liquid $\left(\mathrm{k}_{\mathrm{r}}\right)$ and gaseous $\left(\mathrm{k}_{\mathrm{rg}}\right)$ phases, and a Van Genuchten model (Van Genuchten, 1980) was used to fit the experimental capillary pressure $\left(P_{\text {cap }}\right)$ curve (Fig. 1):

$$
k_{r l}=\hat{S}^{r} \quad \text { and } \quad k_{r g}=(1-\hat{S})^{p} \quad \text { with } \quad \hat{S}=\frac{S_{l}-S_{l r}}{1-S_{l r}-S_{g r}}
$$


where $S_{l}, S_{l r}$ and $S_{g r}$ are the liquid saturation, the irreducible liquid saturation and the irreducible gas saturation, respectively. For the Vosges Sandstone sample, $r=5.5$ and $p=2$. The irreducible water saturation $\left(\mathrm{S}_{\mathrm{r}}\right)$ was 0.19 and the irreducible gas saturation was nil.

$$
P_{\text {cap }}=-P_{0} \cdot\left(\left[S^{*}\right]^{-1 / m}-1\right)^{1-m} \quad \text { with } \quad P_{0}=1.8210^{4} \mathrm{~Pa} \quad ; \quad m=0.675 \quad ; \quad S^{*}=\frac{S_{l}-S_{l r}}{S_{l s}-S_{l r}}
$$

All the parameters used in Eq. (1) and (2) were adjusted from different drainage capillary curves recorded on Vosges Sandstone cores (results not shown here). Specific efforts were made in particular to estimate $P_{0}$, the entry pressure, because it is a key parameter in the prediction of the gas breakthrough. The selected value of 182 mbar was in agreement with values proposed by Peysson (2012).

\subsection{Brine and non-wetting fluid}

Before experiment, Vosges sandstone cores were fully saturated with brine composed of 55 $\% \mathrm{KCl}$ and $45 \% \mathrm{KI}$, the latter intensifying the density contrast for X-ray measurements. According to experiments, water salinity was 35 and $150 \mathrm{~g} / \mathrm{L}$.

The first objective of this work was to determine the drying potential of the gas phase on sandstone plugs. The best solution was to use $\mathrm{CO}_{2}$ in a supercritical state (i.e. at pressures greater than $7.4 \mathrm{MPa}$ and temperatures higher than $31.1^{\circ} \mathrm{C}$ ). But, because of experimental constraints (stability of large volumes of $\mathrm{CO}_{2, \mathrm{sc}}$, maintenance of the devices, problems of injection...), nitrogen replaced $\mathrm{CO}_{2, s c}$ as the non-wetting fluid and temperature and pressure were set to $80^{\circ} \mathrm{C}$ and 50 bars, respectively. In these conditions nitrogen is a gas with drying properties close to those of $\mathrm{CO}_{2}$ (as explained in paragraph 3.1). The experimental results with $\mathrm{N}_{2}$ on core drying were thus comparable with those obtained on experiments performed with $\mathrm{CO}_{2}$. 
In the laboratory, nitrogen was injected into Vosges sandstone cores encapsulated in X-ray transparent cells and placed in an oven under controlled temperature $\left(80^{\circ} \mathrm{C}\right)$ (Fig. 2). The cell is composed of a membrane in order to confine the core at a pressure of 50 bar. Experiments are performed by applying, between the inlet and the outlet of the column, increasing pressure plateaus in one case, and a constant pressure difference in other. The local water saturation in the sample was measured during the injection of dry gas (nitrogen) with X-ray attenuation techniques. The experiments continued until the cores were completely dry. The volume of water expelled was measured in a burette at the column outlet, and a gas flow meter recorded the outlet gas flow rate (Peysson et al., 2010, 2013; Peysson, 2012). Gas permeability and porosity profile of cores were measured at the beginning and at the end of the experiment to evaluate the role of the drying.

\subsection{Experimental results}

For the first experiment, three pressure plateaus (120 mbar, 800 mbar and 1500 mbar) were imposed to the core initially saturated with a $35 \mathrm{~g} / \mathrm{L}$ of brine (Peysson et al., 2013). During the first one, a two-phase flow displacement occurred with a rapid gas breakthrough (at $t=5$ hours) and a low gas flow rate (Fig. 4). The saturation profile in the core showed a typical capillary fringe close to the outlet of the sample. During the second plateau, core continued to desaturate, with a significant contribution of drying. The saturation profiles are flatter because of capillary back flows. For the highest pressure, drying is very rapid, lasting only a few hours. During this phase, a drying front moved from the inlet to the outlet of the core. The dissolved salt, initially present in the brine and transported in the capillary flows, accumulated as precipitate near the injection surface, involving a decrease of about $70 \%$ of the initial permeability.

For the second experiment, a constant difference pressure (300 mbar) was imposed to the core initially saturated with a $150 \mathrm{~g} / \mathrm{L}$ of brine. A rapid gas breakthrough was observed (less 
than 2 hours) with an increase of the gas flow rate up to 26 hours. Then a plugging of the core occurred with no gas flow after 46 hours. The salt accumulation near the injection surface generated by capillary back flows was sufficient to block the gas flow.

\section{MODELLING TOOLS AND NUMERICAL PARAMETERS}

TOUGH2 (Pruess et al., 1999) was used for all of the numerical simulations done in this study (core experiments and field scale). This code couples thermal and hydraulic processes and is applicable to one-, two-, or three-dimensional, physically heterogeneous geologic systems. It is a modular code that can be adapted to a broad range of applications by simply using interchangeable calculation modules. Two modules were used for this study:

- The EOS7C module (Oldenburg et al., 2004) is a fluid property module developed specifically to deal with mixtures of non-condensable gases (like $\mathrm{CO}_{2}$ or $\mathrm{N}_{2}$ ) and methane. It can be used to model isothermal or non-isothermal multiphase flow in water/ $\mathrm{CH}_{4} /\left(\mathrm{CO}_{2}\right.$ or $\left.\mathrm{N}_{2}\right)$ systems. This module uses a cubic equation of state and an accurate solubility formulation along with a multiphase Darcy's Law to model flow and transport of gas and aqueous phase mixtures over a wide range of temperatures and pressures (See Appendix A).

- The ECO2n module (Pruess, 2005) is specificallydeveloped to model isothermal or nonisothermal multiphase flow in water/brine/ $\mathrm{CO}_{2}$ systems in deep geological reservoirs (aquifers or depleted gas fields). It is based on the equilibrium between the supercritical phase and the aqueous phase assumed for $\mathrm{CO}_{2}$ dissolution. Hence,

$$
\mathrm{CO}_{2(\text { sc) }} \quad \Leftrightarrow \quad \mathrm{CO}_{2(\text { aq })}
$$

where(sc) and (aq) denote supercritical and aqueous carbon dioxide, respectively. An extension of Henry's Law is used to estimate the dissolution of $\mathrm{CO}_{2}$ :

$$
\mathrm{K} \Gamma \mathrm{P}=\gamma \mathrm{C}
$$


where $K$ is the equilibrium constant depending on the temperature $T, P$ is the partial pressure of $\mathrm{CO}_{2}, \gamma$ is the aqueous $\mathrm{CO}_{2}$ activity coefficient, $C$ is the aqueous concentration $(\mathrm{mol} / \mathrm{kg}$ $\mathrm{H}_{2} \mathrm{O}$ ), and $\Gamma$ is the fugacity coefficient depending on pressure and temperature.

\subsection{Thermodynamic properties of non-wetting fluids $\left(\mathrm{CO}_{2}\right.$ and $\left.\mathrm{N}_{2}\right)$}

Although our objective is to predict the behaviour of carbon dioxide, laboratory experiments were done with nitrogen in order to avoid ancillary geochemistry mechanisms and focus on the physical effects of drying. Calculations were therefore done to estimate the thermodynamic behaviour of $\mathrm{CO}_{2}$ and $\mathrm{N}_{2}$ and determine how the nature of the fluid might impact the desaturation process. Simulis@ Thermodynamics, a code developed by PROSIM S.A. (http://www.prosim.net), was used to define the fraction of water in the two phases $\left(\mathrm{CO}_{2}\right.$ and $\mathrm{N}_{2}$ ) according to temperature at $80{ }^{\circ} \mathrm{C}$ (Fig. 3). The code integrates various equations of state such as the Peng-Robinson (PR) equation used here for $\mathrm{CO}_{2}$ and $\mathrm{N}_{2}$. The coefficients $\mathrm{K}_{\mathrm{i}, \mathrm{j}}$ used for calculations are those of Soreide and Whitson (1992). The curves obtained with the PR equation were compared to the curve obtained with the Raoult Law (assimilation of $\mathrm{N}_{2}$ and $\mathrm{CO}_{2}$ to perfect gases):

$$
y_{H 2 O, g a s}=\frac{P_{\text {water }, \text { sat }}}{P}
$$

where $\mathrm{P}$ and $\mathrm{P}_{\text {water,sat }}$ are the total pressure and the saturated vapour pressure of water, respectively, calculated with the IAPWS95 equation of state (Wagner and Pruss, 2002). The fraction of water in the supercritical $\mathrm{CO}_{2}$ phase is higher than in the $\mathrm{N}_{2}$ phase (about $30 \%$ at 50 bar and $80^{\circ} \mathrm{C}$ ), whereas the $\mathrm{N}_{2}$ curve is close to the Raoult curve, indicating that $\mathrm{N}_{2}$ can be assimilated to a perfect gas in this range of temperature and pressure(Fig.3). In a first approximation, the substitution of $\mathrm{N}_{2}$ by $\mathrm{CO}_{2}$ in the modelling phase has a limited impact on the results since the evaporation potentials of the two fluidsaresimilar in these pressure and temperature ranges.Onlya shorterdesaturation time is expected using $\mathrm{CO}_{2}$. Moreover, the typeof gas in the model can be changed by calculating the proper thermodynamic coefficients. 
Two sets of calculations were done to study the experimental results. The first set consistedinusing the EOS7C module of the TOUGH2 code to simulate the injection of nitrogen with increasing pressure-steps into a brine-saturated sandstone plug (Fig. 2 and Peysson et al., 2013) in order to determine the time required to desiccate the porous medium and estimate the gas flow rates at the outlet of the core as a function of pressure and temperature (see paragraph 2). A two-phase Darcy's flowequationwas solved using relative permeability and capillary pressure curves. Thermodynamic equilibrium between concomitant phases (water- $\mathrm{N}_{2}$ ), similar to the Eq. (3) defined for $\mathrm{CO}_{2}$, assumes that phase exchanges are responsible for the core drying. This thermodynamic equilibrium is calculated at each time step to determine the watervapour fractionin the gas phase and the fraction of dissolved gas in the brine.

The EOS7C module (version 1.0) does not take into account the salinity of the brine, i.e., it cannot determine either the solubility of the gas in the brine according to its salinity or the amount of salt precipitated inside the core (Oldenburg et al., 2004). Consequently, an additional set of calculations were done with the $\mathrm{ECO} 2 \mathrm{n}$ module in order to determine the quantityand location of the salt deposited in the core. In this simulation, $\mathrm{CO}_{2}$ was injected instead of $\mathrm{N}_{2}$. This simulation was also used to fit the most influential parameters, such as the relationship between porosity and permeability.

In a second set of calculations, the same procedure was used to study the impact of a constant gas injection flow rate and determine the influence of the desaturation path on the deposit locations inside the core.

A 1D-column model $60 \mathrm{~mm}$ long was used as a conceptual framework for determining the evolution of the water content induced by the injection of $\mathrm{N}_{2}$ and $\mathrm{CO}_{2}$ in both time and space. The column was represented by 60 grid blocks making up the mesh. Each grid cell was 1.0 $\mathrm{mm}$ thick. In the lab experiments, the core was cylindrical, whereas in the model, the core is a parallelepiped. The sectionof the parallelepiped is thereforecalculated to obtain the same 
pore volume as the original cylindrical sample. The porous medium (rock matrix) is assumed to be inert with respect to $\mathrm{N}_{2}$ and $\mathrm{CO}_{2}$, i.e. no chemical reactivity. In the next simulations of lab experiments, the initial brine saturating cores only contains sodium chloride.

\subsection{Modelling field applications}

Two sets of calculation were done to study the field scale. In the first set, a 1D-radial model wasused as a conceptual framework for determining the transient evolution of the water content induced by the injection of supercritical $\mathrm{CO}_{2}$ (considered to be a non-wetting fluid). The generic $1 \mathrm{~m}$-thick reservoir was centred around a vertical injection well. The maximum explored radial distancewas $100 \mathrm{~km}$. Along the radius axis, the discretization was very fine close to the well (5 1-mm grid cells, then 52 -mm grid cells, 775 -mm grid cells, and 96010$\mathrm{mm}$ grid cells up to $10 \mathrm{~m}$ from the injection well). There were 100 grid cells between 10 and $100 \mathrm{~m}, 100$ grid cells between $100 \mathrm{~m}$ and $10 \mathrm{~km}$, and 20 grid cells thereafter, up to $100 \mathrm{~km}$. In each interval (between $10 \mathrm{~m}$ and $100 \mathrm{~km}$ ), the width of radial elements followed a logarithmic scale. The objective of such refinement near the injection well was to capture more precisely both the details and the migration of the desiccation front in the near-well region.

In the second set of calculations, a 2D-radial model was used to complement the 1D-radial studies and to include gravity effects. The reservoir was $20 \mathrm{~m}$ thick and hada homogeneous structure. The discretization along the radius axis was the same as the one used for the 1Dradial model.

For both calculations, porosity was $21.8 \%, \mathrm{~K}_{\mathrm{h}}=74 \mathrm{mD}$ and $\mathrm{K}_{v}=7.4 \mathrm{mD}\left(\mathrm{K}_{\mathrm{v}} / \mathrm{K}_{\mathrm{h}}=0.1\right)$. The reservoir was initially fully saturated with sodium chloride brine. Capillary and relative permeability curves are given in figure 1. The initial temperature and pressure of the targeted reservoir were $80{ }^{\circ} \mathrm{C}$ and 180 bar, respectively.No regional flow was considered and a hydrostatic status was initially assumed for the pressure in the reservoir and maintained constant at the lateral boundary. 
For the 1D-radial model, different injection flow rates were used and their impact on the near wellbore integrity was estimated according to the intrinsic rock properties. This was done to estimate the mechanisms able to influence well injectivity. For the 2D-radial model, the injection lasted 10 years with an injection flow rate of $1 \mathrm{~kg} / \mathrm{s}$, distributed on the entire thickness of the reservoir. This is the equivalent of a specific flow rate of $0.050 \mathrm{~kg} / \mathrm{s} / \mathrm{m}$ (total amount of injected $\mathrm{CO}_{2}=315.36 \mathrm{kt}$ ).

\section{Results and Discussions}

\subsection{Modelling core experiments}

\section{Core drying and salt precipitation for desaturation with pressure-steps}

Simulations with TOUGH2's EOS7C module involved modeling the $\mathrm{N}_{2}$ injection in brinesaturated sandstone cores. The salinity of sodium chloride brine was $35 \mathrm{~g} / \mathrm{L}$. Three pressure plateaus $(\Delta \mathrm{P}=0.12,0.80$ and 1.50 bars) were applied between the inlet and the outlet of the column to progressively dry the core. The mean water saturation (calculated from the water saturation in each 1-mm core slice) and the outlet gas flow rates were calculated throughout the injection period, for each pressure step. Results obtained with numerical simulations agree well with experimental data (Fig. 4). During each pressure step, the mean water saturation was well predicted and the value obtained at the end of the second step (for $t=40$ hours) was coherent with the irreducible water saturation $\left(S_{I r}=0.19\right)$. This means that all the mobile water was removed from the core, leaving only the residual water inside the medium.

Despite the application of a low pressure difference, the approaches used were sensitive enough to reproduce the overall evolution of the system, even the outlet gas flow rate. The model was able to accuratelydetermine not only the gas breakthrough timeat the end of step 1 , but also the gas flow rate, regardless of the water saturation inside the column (even when the column is dry). 
At the end of the nitrogen percolation experiment, X-ray measurements revealed the precipitation of salt (halite) inside the porous medium. The new estimated permeability was about $22 \mathrm{mD}$ compared to the initial permeability of $74 \mathrm{mD}$, i.e. a reduction of about $70 \%$ due to salt precipitation. Salt precipitation appearsto be heterogeneous inside the core, with salt accumulating near the injection surface (Peysson, 2012; Peysson et al., 2013).

This precipitation process was modeled with TOUGH2's ECO2n module (see Appendix B). However, to understand the evolution of the permeability inside the core, a relationship between porosity and permeability needs to be selected. Verma and Pruess's "tube-inseries" model (1988) was used because it allows us to reach zero permeability even if porosity is not nil, as experimentallyobserved. It uses the fraction of pore space occupied by precipitated salt and two other parameters: $\Pi$, the fractional length of pore bodies and $\phi_{\mathrm{r}}$, the fraction of initial porosity for which permeability is reduced to zero. The evolution of permeability $\mathrm{K}$, according to the initial permeability $\mathrm{K}_{0}$ is given by:

$$
k_{-} \text {red }=\frac{K}{K_{0}}=\theta^{2} \cdot \frac{1-\Pi+\Pi / \omega^{2}}{1-\Pi+\Pi[\theta /(\theta+\omega-1)]^{2}}
$$

$$
\begin{aligned}
& \text { where } \\
& \theta=\frac{1-S_{S}-\phi_{r}}{1-\phi_{r}} \quad \text { and } \quad \omega=1+\frac{1 / \Pi}{1 / \phi_{r}-1}
\end{aligned}
$$

where $S_{S}$ is the solid saturation, i.e. the pore space volume occupied by precipitated salt. Usually, $\Pi=\phi_{r}=0.80$ as given in Pruess et al. (1999) and by various other authors (Alkan et al., 2010).

Calculations done with these Пand $\phi_{r}$ valuesunderestimated the decrease in permeability. The values were therefore modified and optimized in order to fit a decrease in permeability coherent with experimental data. This was achieved with $\Pi=0.80$ and $\phi_{r}=0.91$, i.e. a drastic decrease in permeability for a low decrease in porosity (Fig. 5). These values are not out of range since they have already been used in a geothermal field in the Philippines where silica scaling causes high permeability decreases (Xu et al., 2004). These results are also in agreement with the values obtained by Peysson (2012). 
Calculations done with these new parameter values gaveadecrease in permeability of around55-60 \% of the initial permeability, which is not too far from the $70 \%$ determined in the experiment. The mean permeability was about $31 \mathrm{mD}$ (compared to an initial $74 \mathrm{mD}$ ), with some variations around this value probably due to the boundary conditions chosen for these simulations(Fig. 6). The total amount of precipitated salt was about $1.73 \mathrm{~g}$ (compared to the $3.73 \mathrm{~g}$ of salt initially dissolved in the original pore water). Figure 6 also shows a large decrease in permeability in the first millimetre, as observed in the experiments. This is due to the accumulation of salt close to the injection zone in agreement with X-ray adsorbance measurements (Fig. 7) (Peysson et al., 2013).

The interpretation of these results enabled us to determine the $k / \Phi$ relationship. The objective was then to apply this approach to another kind of simulation and to determine whether the results of numerical simulations were in agreement with experimental observations.

\section{Salt precipitation for desaturation with a constant pressure difference}

A sandstone core saturated with brine enriched in $\mathrm{KCl}(150 \mathrm{~g} / \mathrm{L})$ was dried in the laboratory with a constant pressure difference. The nitrogen flow rate at the outlet of the core decreased to zero during the experiment, which shows that clogging occurred inside the core (Peysson, 2012; Peysson et al., 2013). This experiment was modeled with the ECO2n module, by injecting $\mathrm{CO}_{2}$ with a constant pressure difference of 0.3 bar. The previously determined $\mathrm{k} / \Phi$ relationship was used to simulate the loss of permeability generated by the deposition of salt inside the core. In the simulation, because of sodium chloride brine, the precipitation of halite is examined.

The precipitation profile obtained numericallyshows zero permeability close to the injection point and relatively high values close to thecolumn outlet (Fig. 6). About $1.81 \mathrm{~g}$ of salt precipitated $-1.11 \mathrm{~g}$ in the first half of the column and $0.70 \mathrm{~g}$ in the second half, indicating a massive precipitation close to the column inlet. 
Figure 7 shows that salt accumulated in the first millimeters of the core, close to the injection zone. This explains the clogging observed in our experiments (permeability reduced to zero).The results were compared to those obtained in the previous experiment, i.e. the drying according to pressure steps. The shapes of the curves are the same, with a homogeneous deposition of salt throughout the columns, except in the first millimeters where there is clogging. This can be explained by fluid (non-wetting and water) displacement inside the core. Numerical calculations showed that:

- Before the gas reaches the column outlet, both fluids (water and non-wetting) move from the inlet to the outletof the core. Gas is injected in the column and pushes "free" water out of the core.

- When the gas flow rate is measured at the outlet of the core (i.e. when the column is partially desaturated), the gas continues to move from the inlet to the outlet of the column, whereas water moves in the other direction.

Gas injection results in water back-flowinside the desaturated core due to capillary forces. This transports dissolved salt towards the injection point where evaporation is a predominant mechanism. Consequently, a large amount of salt precipitates, accumulatesand has an impact on porosity and then on permeability.

The influence of the injection flow rate on the amount of salt deposited in the core cannot be assessed with these two experiments because the brines used did not have the same initial salinity. This is, however, discussed below.

\subsection{Modelling at field scale (1D-radial approach)}

In order to understand multiphase flow during $\mathrm{CO}_{2}$ injection in saline aquifers, we extrapolated to field scale, first with a $1 \mathrm{D}$ and then with a 2D radial model (see paragraph 3.3). For these simulations, we considered that the set of $k_{r}-P_{c}$ parameters used for predictive simulation at the core scale would enable modeling of $\mathrm{CO}_{2}$ injection at the reservoir scale. Bennion and Bachu (2005) advised that relative permeability characteristics have to be 
determined under reservoir conditions to accurately parameterize reservoir models. However, Egermann et al. (2006)demonstrated that both experiments and large scale applications can be simulated using a single set of parameters. The predictive model for $\mathrm{CO}_{2}$ injection at the reservoir scale is sufficiently accurate if gas-water relative permeability curves and thermodynamic data (solubility of $\mathrm{CO}_{2}$ in the liquid water phase and water vapour pressure in the $\mathrm{CO}_{2}$ gas phase) are taken into account in the model. Since TOUGH2 code uses the thermodynamic and thermophysical properties (density, viscosity and enthalpy) of the non-wetting $\mathrm{CO}_{2}$ phase and the $\mathrm{k}_{\mathrm{r}}-\mathrm{P}_{\mathrm{c}}$ curves for simulations, we used, as an approximation, a single set of parameters to extrapolate to the reservoir scale.

Numerical simulations were then done at 180 bar and $80{ }^{\circ} \mathrm{C}$, although the $\mathrm{P}_{c}$ curve was drawn for 50 bars and $80{ }^{\circ} \mathrm{C}$. The $\mathrm{P}_{\mathrm{c}}$ curve could have been modified using the Leverett function to take into account this differencein pressure. However, since the gas-brine interfacial tension (IFT) between 50 and 180 bars does not change considerably (Chiquet et al., 2007; Chalbaud et al., 2009), the Pc curve shown in figure 1 was used in a first approximation.

The 1D numerical simulations were done to study the possible correlation between brine salinity (sodium chloride content), $\mathrm{CO}_{2}$ injection flow rate and the spatial distribution of salt (halite) precipitation. Sensitivity calculations are done to test the behavior of the system with respect to these parameters. First, $\mathrm{CO}_{2}$ was injected into a reservoir containing brine. Two salinities were tested, 10 and $100 \mathrm{~g} / \mathrm{L}$, while the same over pressure was applied between the well and the reservoir $(\Delta \mathrm{P}=2$ bars, equivalent to a mean injection flow rate of about $0.015 \mathrm{~kg} / \mathrm{s} / \mathrm{m})$

As expected, based on the core scale experiments, supercritical $\mathrm{CO}_{2}$ injection caused the drying of the porous medium around the well, but results differed depending on brine salinity. The impact on permeability was much greaterfor the more concentrated brine, with probable clogging near the injection point (Fig. 8). The impact on permeability was not limited to the near-well zone but extended inside the reservoir formation. These calculations show that the 
amount of precipitated salt is directly related to the salinity of the brine initially present in the porous medium.

Simulations were also done to determine whether clogging might be prevented with a different injection flow rate. The same simulation as above was donewith three different pressure differences between the well and the reservoir. For low salinities $(10 \mathrm{~g} / \mathrm{L})$ and $\Delta \mathrm{P}>$ 5 bars (for a mean injection flow rate $>0.045 \mathrm{~kg} / \mathrm{s} / \mathrm{m}$ ), salt precipitation affected the permeability of the porous medium only slightly (about $5 \%$ decrease in permeability) (Fig. 9a). When the injection pressure decreased (low $\Delta \mathrm{P}$ and low injection flow rates of around 0.010 to $0.015 \mathrm{~kg} / \mathrm{s} / \mathrm{m}$ ), the quantities of precipitated salts increased and the near wellbore porous medium became clogged when the injection flow rate was lower than $0.010 \mathrm{~kg} / \mathrm{s} / \mathrm{m}$.

For higher brine salinities (100 and $160 \mathrm{~g} / \mathrm{L})$, the application of strong over pressure $(\Delta P=15$ to 40 bars, equivalent to mean injection flow rates of about 0.120 to $0.500 \mathrm{~kg} / \mathrm{s} / \mathrm{m}$ ) caused the precipitation of salts around the injector well, decreasing the permeability by about 40 and $60 \%$ for brine salinities of 100 and $160 \mathrm{~g} / \mathrm{L}$, respectively (Fig. 9a). When the over pressure decreased (injection flow rates lower than 0.030 to $0.050 \mathrm{~kg} / \mathrm{s} / \mathrm{m}$ depending on brine salinity), salt precipitation increasedup to the clogging of the near wellbore domain.

The over pressure used to inject $\mathrm{CO}_{2}$ needs, therefore, to be adapted to the salinity of the native aqueous solution and the petrophysical properties ( $\mathrm{K}, \mathrm{kr}, \mathrm{Pc}$ and $\phi)$ of the host reservoir. This sensitivity study showed thatwhen the $\mathrm{CO}_{2}$ injection flow rate is too low, a porous medium could become clogged near the injection well even in the presence of a low salinity-brine. An analogy can be made between the gas flow rate and the Pécletnumber $(\mathrm{Pe})$ reported by Peysson (2012) and Peysson et al. (2013). For each salinity/injection flow rate couple, there is a threshold gas flow rate $\left(Q_{t}\right)$ and a limit Péclet number (Fig. 9b). For the Vosges sandstone, a brine salinity of $10 \mathrm{~g} / \mathrm{L}$ entails a threshold gas flow rate of about 0.010 $\mathrm{kg} / \mathrm{s} / \mathrm{m}$ (equivalent to a Péclet number of 430 ), whereas for higher brine salinity, $\mathrm{Q}_{\mathrm{t}}$ increases up to $0.030 \mathrm{~kg} / \mathrm{s} / \mathrm{m}(P e=1200)$ and $0.050 \mathrm{~kg} / \mathrm{s} / \mathrm{m}(P e=2000)$ for salinities of $100 \mathrm{~g} / \mathrm{L}$ and 160 $\mathrm{g} / \mathrm{L}$, respectively. Below these threshold values, the system clogs due to the capillary back 
flow that moves brine (and dissolved salts) toward the injection point generating/stabilizing an evaporation aureole accumulating salt deposits. The water is evaporated by the continuous injection of gas, leaving solid salt behind reducing permeability to zero according to the $\mathrm{k} / \Phi$ relationship used for this sandstone. These numerical results are in agreement with laboratory experiments done with this Vosges sandstone (Peysson et al., 2013). These authors observed a clogging of the core with a brine salinity of $150 \mathrm{~g} / \mathrm{L}$ and $\mathrm{Pe}=360$. However, when the injection flow rate was higher than the threshold value, two-phase displacement seems to be the main process - the water saturation close to the injection surface was sufficiently low to decrease the capillary back flow and limit the back flow of dissolved salts. Salt precipitation near the injection point was thus lowered and salts tended to be deposited farther from the sensitive and strategic near-wellbore zone. Salt precipitated more homogeneously throughout a large near-wellbore zone, decreasing the global permeability of the medium but not clogging the core. In all of these calculations, salt diffusion was disregarded. Indeed, given the high Péclet number values, this hypothesis is valid.

\subsection{Modelling at field scale (2D-radial approach)}

A 2D-radial system was considered in order to develop an integrated approach able to represent the coupling of different thermodynamic mechanisms (such as the evaporation of brine and the equilibrium between gas and liquid phases) and physical processes (such as the transport of a non-wetting supercritical fluid in a saline reservoir, gravity and capillary forces, etc.). We simulated the uniform and continuous injection of $\mathrm{CO}_{2}$ along the entire thickness of the reservoir for 10 years. The reservoir was initially saturated with sodium chloride $(\mathrm{NaCl})$ brine with a salinity of $160 \mathrm{~g} / \mathrm{L}$. The specific injection flow rate used $(0.050$ $\mathrm{kg} / \mathrm{s} / \mathrm{m}$ ) was voluntarily close to the $Q_{t}$ value defined for the 1D-radial model. The objective was to determine whether the clogging predicted by the 1D-radial model for this injection flow rate and brine salinity also occurs on the $2 \mathrm{D}$-radial model. 
Because of gravity forces and the supercritical $\mathrm{CO}_{2}$ density (lower than that of the brine), the reservoir dries outfasterat the top.Figure 10a clearly shows that the porous medium is dry over about $12 \mathrm{~m}$ at the top of the reservoir, whereas only the first meter is dryat the bottom. Inside the drying zone, solid salt (i.e., halite) precipitates. Although salt is present in all of thedesaturated zone, the spatial distribution of salt deposits varies according to the prevalent transport forces (advection, diffusion, capillarity, evaporation, etc.) inside the reservoir: the quantities are higher at the bottom of the reservoir and more limited at the top (Fig. 10b) for simulation conditions and the specific characteristics of the reservoir. The pattern of solid saturation (= solid volume/pore volume) indicates that $40 \%$ of the porosity is filled with salt at the bottom, whereas only $10 \%$ is filled at the top. According to the $k / \Phi$ law established in paragraph 4.1 , the porosity and consequently the permeability are more impacted at the bottom of the reservoir (Fig. 10c). The decrease in permeability is represented by the empirical function k-red $\left(=\mathrm{K} / \mathrm{K}_{0}\right)$. This function clearly shows that high permeability reductions are expected near the well (skin effect in the cells adjacent to the well) and in the lower part of the reservoir (in the first meter inside the reservoir).

To explain this distribution of salt inside the reservoir and the massive deposits at the bottom of the aquifer, it is necessary to plot the fluid flows inside the reservoir. Figure 11 shows the directions and trajectories of gas (a) and brine (b) flow inside the reservoir, which initially had a homogeneous structureand petrophysical propertiesthatfacilitated fluid circulation throughout the entire thickness $(20 \mathrm{~m})$. The lengths of the flow vectors drawn for each grid cell are proportional to the intensity of the flow. The arrows show direction. The vectors are centered on the grid cells.

$\mathrm{CO}_{2}$ vectors are oriented from left (the well) to right, with some deviation towards the top of the reservoir (Fig. 11a). The vertical permeability, ten times lower than the horizontal permeability, limits upward flow, but this is clearly seen in this figure. This figure also shows that gas fluxes are higher in the upper part of the reservoir (between $z=10$ and $20 \mathrm{~m}$ ), which explains the shorter time required to desaturate this zone and its lateral extension. 
Brine fluxes in the reservoir are more complex (Fig. 11b). Trends differ depending on the location in the aquifer. Close to the well and withina radius of about $30 \mathrm{~m}$, brine flows toward the injector whereas the gas phase flows away from it. Far from the well, the water flows from left to right and from up to down. Beyond $30 \mathrm{~m}$, the gas phase displaces the water by a piston effect from left to right and, because the gas phase is less dense, the brine is pushed downwards, the size of the arrows indicating the intensity. Close to the well $(0-30 \mathrm{~m})$, brine flows towards the injection well. Saline water flows towards the well due to capillary forces that compete with the evaporation process. The length of the arrows shows that the highest flows are at the bottom of the reservoir. In this reservoir zone, capillary forces are great enough to move water in grid cells very closed to the well. These flows move the water, which is then evaporated by the continuous injection of desiccant fluid $\left(\mathrm{CO}_{2}\right)$, depositing large quantities of salt in this region. At the top of the reservoir, the capillary brine back flows are weaker and less salt is therefore deposited.

This simulation shows that a $\mathrm{CO}_{2}$ injection specific flow rate of $0.050 \mathrm{~kg} / \mathrm{s} / \mathrm{m}$ causes the clogging of the porous medium in the lower part of the reservoir where capillary brine flows are higher (in agreement with 1D-radial model results). As expected from laboratory experiments, the permeabilityis cloggedby salt depositsbecause of the injection flow rate which is below the $Q_{t}$ value. These results were obtained for a homogeneous reservoir $20-m$ thick(Figure 12). Although clogging occurs in the lower part of the reservoir, the well injectivity is only moderately altered. However, reservoirs are usually highly heterogeneous and very often made up of thick layers separated by less permeable layers that limit vertical flow. Gas cannot move vertically. Consequently, each reservoir compartment can be considered to be a 1D case with major horizontal gas flows and capillary effects in each subdomain. Clogging risks are increased in each compartment with a potentially strong impact on well injectivity. 
This study clearly shows that a specific integrated approach is necessary in order to take into consideration both thermodynamic mechanisms and physical processes and adapt injection conditions to reservoir properties.

\section{Conclusions}

Drying processes were studiedwith laboratory experiments and numerical simulations in order to determine the dynamics of the decrease in water saturation in sandstone and the consequences of induced salt depositions on rock permeability. Experiments at the laboratory scale revealed the major role played by capillary forces and the salinity of the initial brine on the changes in permeability. These experiments also highlighted the relationship between salt deposits, gas injection flow rate and the capillary properties of the porous medium subjected to non-wetting fluid injection, and demonstrated the need to use a coupled and dynamic approach to fully represent the mechanisms involved.

The numerical code used in this study was able to accurately reproduce both the evolutions of the water content in sandstone cores and the salt precipitation with a given brine salinity and various $\mathrm{CO}_{2}$ injection flow rates. The thermodynamic and physical processes were well simulated at small scale on a homogeneous porous material.

Based on our experimental results (rocks characteristics) and several hypotheses (such as the extension of $\mathrm{kr} / \mathrm{Pc}$ curves obtained at laboratory scale to a large scale, the homogeneity of the reservoir), this study also investigated the behaviors of water, salt and a non-wetting fluid at the reservoir scale, and more precisely in the near-well zone. This integrated approach combining experimental and numerical simulations showed that the salt precipitation process and the amount of salt deposited are related to various parameters such as the salinity of the initial brine. The higher the brine concentration, the greater the salt deposit. However, the location of the deposits inside the reservoir is strongly linked to the supercritical non-wetting fluid injection flow rate and the capillary forces generating backflows. The numerical simulations showed that the capillary properties of the rock prevent a 
sudden evaporation of the irreducible water by continuously feeding the injection zone with "new" brine coming from reservoir zones far from the injection well. However, a sufficiently high gas injection rate can overcome the capillary forces and limit the precipitation of salts close to the injection well. Sensitivity analysis made it possible to determine a threshold gas flow rate $\left(Q_{t}\right)$ dependent on brine salinity. Below this threshold value, there is a high risk of clogging, whereas higher values $\left(Q>Q_{t}\right)$ can reduce the risk of clogging. However, if high gas injection flow rates in high saline aquifers can prevent clogging, decreased permeability is expected, even far from the injection well zone.

This study highlights that all these parameters ( $\mathrm{kr} / \mathrm{Pc}$ curves, brine salinity, pressure and $\mathrm{CO}_{2}$ injection flow rates) must be known in order to improve the management of the industrial injection of $\mathrm{CO}_{2}$ in saline aquifers. The real structure of the reservoir as its heterogeneity (not considered in this study) has also to be taken into account as a key parameter because it could modify the capillary fluxes and thus, the localisation of the salt deposits.

\section{Acknowledgements}

This work was carried out within the framework of the "ProchePuits" project, co-funded by the French National Agency for Research (ANR). The authors thank Marc Parmentier (BRGM) calculating the water content in the gas phases with the Simulis@ $\odot$ Thermodynamics code. Theyare grateful to all of the project partners (TOTAL, GDF Suez, Schlumberger, Itasca, CNRS, University de Lorraine, University of Pau) for authorizing the publication of this work. 
In TOUGH2 Code, the mass conservation equations governing the flow of multiphase, multicomponent fluids in permeable media can be written in the following form:

$$
\frac{d}{d t} \int_{V_{n}} M^{\kappa} d V_{n}=\int_{\Gamma_{n}} F^{\kappa} \cdot d \Gamma_{n}+\int_{V_{n}} q^{\kappa} d V_{n}
$$

The integration is over an arbitrary subdomain $V_{n}$ of the flow system under study, which is bounded by the closed surface $\Gamma_{n}$. The quantity $M$ appearing in the accumulation term (left hand side) represents mass per volume, with $k=1, \ldots, N K$ labeling the components (water, $\mathrm{NaCl}, \mathrm{CO}_{2}$ ). $F$ denotes mass flux (see below), and $q$ denotes sinks and sources. $n$ is a unit normal vector on surface element $d \Gamma_{n}$, pointing inward into $V_{n}$. Eq. (A1) expresses the fact that the rate of change of fluid mass in $V_{n}$ is equal to the net inflow across the surface of $V_{n}$, plus net gain from fluid sources.

The general form of the accumulation term is:

$$
M^{\kappa}=\phi \sum_{\beta} S_{\beta} \rho_{\beta} X_{\beta}^{\kappa}
$$

In Eq. (A2), the total mass of component $\kappa$ is obtained by summing over the fluid (= liquid, gas) and solid phases $\beta$. $\phi$ is porosity, $S_{\beta}$ is the saturation of phase $\beta$ (i.e., the fraction of pore volume occupied by phase $\beta$ ), $\rho_{\beta}$ is the density of phase $\beta$, and $X_{b}{ }^{k}$ is the mass fraction of component $\kappa$ present in phase $\beta$.

Advective mass flux is a sum over phases,

$$
F^{\kappa}=\sum_{\beta} X_{\beta}^{\kappa} F_{\beta}
$$

and individual phase fluxes are given by a multiphase version of Darcy's law:

$$
F_{\beta}=\rho_{\beta} \cdot u_{\beta}=-k \cdot \frac{k_{r \beta} \cdot \rho_{\beta}}{\mu_{\beta}} \cdot\left(\nabla P_{\beta}-\rho_{\beta} \cdot g\right)
$$

Here $u_{\beta}$ is the Darcy velocity (volume flux) in phase $\beta, k$ is absolute permeability, $k_{r \beta}$ is relative permeability to phase $\beta$, $\mu_{\beta}$ is viscosity, and $P_{\beta}$ (the fluid pressure in phase $\beta$ ) is the sum of the pressure $P$ of a reference phase (usually taken to be the gas phase), and the capillary pressure $P_{c \beta}(\leq 0) . g$ is the vector of gravitational acceleration. TOUGH2 simulator also considers diffusive fluxes in all phases, and includes coupling between diffusion and phase partitioning that can be very important for volatile solutes in multiphase conditions (Pruess, 2002). Diffusive flux of component $\kappa$ in phase $b$ is given by

$$
f_{\beta}^{\kappa}=-\phi \tau_{0} \tau_{\beta} \rho_{\beta} d_{\beta}^{\kappa} \nabla X_{\beta}^{\kappa}
$$

where $\tau_{0} \tau_{\beta}$ is the tortuosity which includes a porous medium dependent factor $\tau_{0}$ and a coefficient that depends on phase saturation $S_{\beta}, t_{\beta}=t_{\beta}\left(S_{\beta}\right)$, and $d_{\beta}{ }^{k}$ is the diffusion coefficient 
of component $\kappa$ in bulk fluid phase $\beta$. Special TOUGH2 versions that include a conventional Fickian model for hydrodynamic dispersion have also been developed, but this option is not activated in the present study (see $§ 4.2$ for more explanations).

By applying Gauss' divergence theorem, equation (A1) can be converted into the following Partial Differential Equation (PDE):

$$
\frac{d M^{\kappa}}{d t}=-\operatorname{div} F^{\kappa}+q^{\kappa}
$$

which is the form commonly used as the starting point for deriving finite difference or finite element discretization approaches. However, in TOUGH2 an "integral finite difference" method (Narasimhan and Witherspoon, 1976) is used, in which space discretization is directly applied to the integrals in Eq. (A1).

The calculation of thermophysical properties for water/ $\mathrm{NaCl} / \mathrm{CO}_{2}$ mixtures appearing in the equations given above is described in the ECO2n user's guide (Pruess, 2005).

\section{Appendix B : Details about precipitation/dissolution of sodium chloride}

The TOUGH2 code includes several Equation of State (EOS) modules developed specifically for treating different mixtures in order to solve problems in the fields of hydrogeology, geothermal and petroleum engineering, nuclear waste disposal, and environmental pollution (Pruess, 1999). The ECO2n EOS module (Pruess, 2005) was developed to simulate flow problems in which the transport of a variable salinity brine and a Non Condensible $\mathrm{Gas}\left(\mathrm{CO}_{2}\right)$ occurs. The multiphase system is assumed to be composed of three mass components: water, sodium chloride, and carbon dioxide. Whereas water and $\mathrm{CO}_{2}$ components may be present only in the liquid and gas phases, the salt component may be dissolved in the liquid phase or precipitated to form a solid salt phase.

The treatment of precipitation/dissolution of sodium chloride has been introduced using the method employed to treat similar phenomena occurring for water-silica mixtures (Verma and Pruess, 1988). Dissolved salt concentration is characterized in ECO2n module by means of a specific primary variable $\mathrm{x}_{\mathrm{NaCl}}$ (fraction of total $\mathrm{H}_{2} \mathrm{O}+\mathrm{NaCl}$ mass). This variable is restricted to the range $0 \leq \mathrm{x}_{\mathrm{NaCl}} \leq \mathrm{x}_{\mathrm{eq}}$, where $\mathrm{x}_{\mathrm{eq}}$ is the solubility of salt according to temperature (Potter et al. 1977, Chou 1987):

$$
\mathrm{x}_{\mathrm{eq}}=0.26218+7.210^{-5} . T+1.0610^{-6} . T^{2}
$$

with $\mathrm{T}$ in ${ }^{\circ} \mathrm{C}$. When salt concentration $\left(\mathrm{x}_{\mathrm{NaCl}}\right)$ exceeds salt solubility $\left(\mathrm{x}_{\mathrm{eq}}\right)$, this corresponds to conditions in which solid salt will be present in addition to dissolved salt in the aqueous phase. The mass of precipitated salt is then calculated and used to evaluate the reduction of rock porosity, as well as the related formation permeability, according to relationships given in the text (see § 4.1). 


\section{References}

Alkan, H., Cinar, Y., Ülker, E. B., 2010. Impact of Capillary Pressure, Salinity and In situ Conditions on $\mathrm{CO}_{2}$ Injection into Saline Aquifers. Transport in Porous Media 84, 799819.

André, L., Audigane, P., Azaroual, M., Menjoz, A., 2007. Numerical modeling of fluid-rock chemical interactions at the supercritical $\mathrm{CO}_{2}$-liquid interface during supercritical carbon dioxide injection into a carbonated reservoir, the Dogger aquifer (Paris Basin, France). Energy Conversion and Management 48, 1782-1797.

André, L., Azaroual, M., Menjoz, A., 2010. Numerical Simulations of the Thermal Impact of Supercritical $\mathrm{CO}_{2}$ Injection on Chemical Reactivity in a Carbonate Saline Reservoir. Transport in Porous Media 82 (1), 247-274.

Audigane, P., Gaus, I., Czernichowski-Lauriol, I., Pruess, K., Xu, T., 2007. Two-dimensional reactive transport modeling of $\mathrm{CO}_{2}$ injection in a saline Aquifer at the Sleipner site, North Sea. American Journal of Science 307, 974-1008.

Bennion, B., Bachu, S., 2005. Relative permeability characteristics for supercritical $\mathrm{CO}_{2}$ displacing water in a variety of potential sequestration zones in the Western Canada sedimentary basin. SPE 95547. SPE Annual Technical Conference and Exhibition, Dallas, USA, 9-12 October 2005.

Bielinski, A., Kopp, A., Schütt, $\mathrm{H}$., Class, $\mathrm{H}$., 2008. Monitoring of $\mathrm{CO}_{2}$ plumes during storage in geological formations using temperature signals: numerical investigation. International Journal of Greenhouse Gas Control 2, 319-328.

Chiquet, P., Daridon, J.L., Broseta, D., Thibeau, S., 2007. $\mathrm{CO}_{2} /$ water interfacial tensions under the pressure and conditions of geological storage. Energy Conversion and Management 48, 736-744.

Chalbaud, C., Robin, M., Lombard, J.-M., Egermann, P., Bertin, H., 2009. Interfacial tension measurements and wettability evaluation for geological $\mathrm{CO}_{2}$ storage, Advances in Water Resources 32, 98-109. 
Chou, I.-M., 1987. Phase relations in the system $\mathrm{NaCl}-\mathrm{KCl}-\mathrm{H}_{2} \mathrm{O}$. III: Solubilities of halite in vapor-saturated liquids above $445^{\circ} \mathrm{C}$ and redetermination of phase equilibrium properties in the system $\mathrm{NaCl}-\mathrm{H}_{2} \mathrm{O}$ to $1000^{\circ} \mathrm{C}$ and 1500 bars. Geochimica Cosmochimica Acta 51, 1965-1975.

Corey, A.T., 1954. The interrelation between gas and oil relative permeabilities. Producers Monthly, 38-41, November 1954.

Egermann, P., Chalbaud, C., Duquerroix, J.-P., Le Gallo, Y., 2006. An Integrated Approach to Parameterize Reservoir Models for $\mathrm{CO}_{2}$ Injection in Aquifers. SPE 102308. SPE Annual Technical Conference and Exhibition, San Antonio, USA, 24-27 September 2006.

Ennis-King, J., Paterson, L., 2007. Coupling of geochemical reactions and convective mixing in the long-term geological storage of carbon dioxide. International Journal of Greenhouse Gas Control 1 (1), 86-93.

Giorgis, T., Carpita, M., Battistelli, A., 2007. 2D modeling of salt precipitation during the injection of dry $\mathrm{CO}_{2}$ in a depleted gas reservoir. Energy Conversion and Management 48, 1816-1826.

Huq, F., Blum, P., Marks, M.A.W., Nowak, M., Haderlein, S.B., Grathwohl, P., 2012. Chemical changes in fluid composition due to $\mathrm{CO}_{2}$ injection in the Altmark gas field: preliminary results from batch experiments. Environmental Earth Sciences 67 (2), 385394.

Hurter, S., Labregere, D., Berge, J., 2007. Simulations for $\mathrm{CO}_{2}$ injection projects with compositional simulator. SPE 108540. Offshore Europe 2007 Conference, Aberdeen, Scotland, 4-7 September 2007.

Kim, M., Sell, A., Sinton, D., 2013. Aquifer-on-a-chip: understanding pore-scale salt precipitation dynamics during $\mathrm{CO}_{2}$ sequestration. Lab on a chip, doi:10.1039/c3lc00031a.

Kleinitz, W., Tölcke, W., 1982. Bildungsbedingungen von Ablagerungen in Gasbohrungen und deren Beseitigung; Erdöl-Erdgas-Zeitschr., 4. 
Kleinitz, W., Koehler, M., Dietzsch, G., 2001. The Precipitation of Salt in Gas Producing Wells. SPE 68953. SPE European Formation Damage Conference, The Hague, The Netherlands, 21-22 May 2001.

Kleinitz, W., Dietzsch, G., Köhler, M., 2003. Halite scale formation in gas producing wells. Chemical Engineering Research and Design81 (PartA).

Kopp, A., Ebigbo, A., Bielinski, A., Class, H., Helmig, R., 2009. Numerical simulation of temperature changes caused by $\mathrm{CO}_{2}$ injection in geological reservoirs. in M. Grobe, J. C. Pashin, and R. L. Dodge, eds., Carbon dioxide sequestration in geological mediaState of the science: AAPG Studies in Geology 59, 439-456.

Leroy, P., Lassin, A., Azaroual, M., André, L., 2010. Predicting the surface tension of aqueous 1:1 electrolyte solutions at high salinity. Geochimica and Cosmochimica Acta 74, 5427-5442.

Mahadevan, J., 2005. Flow-through drying of porous media. PhD Dissertation. The University of Texas at Austin.

Mahadevan, J., Sharma, M.M., Yortsos, Y.C., 2007. Water removal from porous media by gas injection: experiments and simulation. Transport in Porous Media 66, 287-309.

Mehnert, E., Okwen, R.T., 2012. Near-well pressure distribution of $\mathrm{CO}_{2}$ injection in a partially penetrating well. Proceedings of TOUGH Symposium 2012, Lawrence Berkeley National Laboratory, Berkeley, California, 17-19 September 2012.

Narasimhan, T.N., Witherspoon P. A., 1976. An integrated finitedifference method for analyzing fluid flow in porous media. Water Resources Research 12(1), 57-64.

Okwen, R.T., Stewart,M.T., Cunningham, J.A., 2011. Temporal variations in near-wellbore pressuresduring $\mathrm{CO}_{2}$ injection in saline aquifers. InternationalJournal of Greenhouse Gas Control 5(5), 1140-1148.

Oldenburg, C.M., Moridis, G.J., Spycher, N., Pruess, K., 2004. EOS7C Version 1.0: TOUGH2 Module for Carbon Dioxide or Nitrogen in Natural Gas (Methane) Reservoirs. Lawrence Berkeley National Laboratory Report LBNL-56589, Berkeley, CA (USA). 
Ott, H., de Kloe, K., Marcelis, F., Makurat, A., 2010a. Injection of Supercritical $\mathrm{CO}_{2}$ in Brine Saturated Sandstone: Pattern Formation during Salt Precipitation. Energy Procedia 4, $4425-4432$.

Ott, H., de Kloe, K., Taberner, C., Marcelis, F., Wang, Y., Makurat A., 2010b. Rock/fluid interaction by injection of Supercritical $\mathrm{CO}_{2} / \mathrm{H}_{2} \mathrm{~S}$ : Investigation of dry-zone formation near the injection well. International Symposium of the Society of Core Analysts (SCA2010-20), Halifax, Nova Scotia, Canada, 4-7 October 2010.

Peter-Borie, M., Blaisonneau, A., Gentier, S., Rachez, X., Shiu, W., Dedecker, F., 2011. A particulate rock model to simulate thermo-mechanical cracks induced in the near-well by supercritical $\mathrm{CO}_{2}$ injection. Annual Conference of the International Association for Mathematical Geosciences, Salzburg, Austria, 5-9 September 2011.

Peysson, Y., Bazin, B., Magnier, C., Kohler, E., Youssef, S., 2010. Permeability alteration due to salt precipitation driven by drying in the context of $\mathrm{CO}_{2}$ injection. International Conference on Greenhouse Gas Technologies (GHGT-10), Amsterdam, 19-23 September 2010.

Peysson, Y., 2012. Permeability alteration induced by drying of brines in porous media. The European Physical Journal - Applied Physics 60, 24206p1-p12.

Peysson, Y., André, L., Azaroual, M., 2013. Well injectivity during $\mathrm{CO}_{2}$ injection in deep saline aquifers -Part 1: Experimental investigations of drying effects and salt precipitation. International Journal of Greenhouse Gas Control, same issue.

Potter, R.W., Babcock, R.S., Brown, D.L., 1977. A new method for determining the solubility of salts in aqueous solutions at elevated temperatures.Journal of Research of the U.S. Geological Survey 5(3), 389-395.

Pruess, K., Oldenburg, C.M., Moridis,G.J., 1999. TOUGH2 User's Guide, Version 2.0. Lawrence Berkeley National Laboratory Report LBNL-43134, Berkeley, CA (USA).

Pruess, K., 2002. Numerical simulation of multiphase tracer transport infractured geothermal reservoirs, Geothermics 31, 475-499. 
Pruess, K., 2005.ECO2n: a TOUGH2 fluid property module for mixtures of water, $\mathrm{NaCl}$ and $\mathrm{CO}_{2}$. Lawrence Berkeley National Laboratory Report LBNL-57952, Berkeley, CA (USA).

Pruess, K., Müller, N., 2009. Formation dry-out from $\mathrm{CO}_{2}$ injection into saline aquifers: 1. Effects of solids precipitation and their mitigation, Water Resources Research, 45, W03402

Soreide, I., Whitson, C.H, 1992. Peng-Robinson predictions for hydrocarbons, $\mathrm{CO}_{2}, \mathrm{~N}_{2}$, and $\mathrm{H}_{2} \mathrm{~S}$ with pure water and $\mathrm{NaCl}$ brine. Fluid Phase Equilibria 77, 217-240.

Sterpenich, J., Renard, S., Pironon, J., 2006. Reactivity of French Triassic sandstones submitted to $\mathrm{CO}_{2}$ under deep geological storage conditions. In Proceeding of $8^{\text {th }}$ International Conference on Greenhouse Gas Control Technologies, 19-22 June 2006, Trondheim, Norway.

Van Genuchten, M.T., 1980. A closed-form equation for predicting the hydraulic conductivity of unsaturated soils. Soil Science Society of America Journal 44, 892-898.

Vandeweijer, V., Van der Meer, B., Hofstee, C., 2011. Monitoring the $\mathrm{CO}_{2}$ injection site : K12B. Energy Procedia 4, 5471-5478.

Verma, A., Pruess,K., 1988. Thermohydrologic conditions and silica redistribution near highlevel nuclear wastes emplaced in saturated geological formations.Journal of Geophysical Research 93 (B2), 1159- 1173.

Vilarrasa, V., 2012. Thermo-Hydro-Mechanical Impacts of Carbon Dioxide $\left(\mathrm{CO}_{2}\right)$ Injection in Deep Saline Aquifers. PhD Thesis. Department of Geotechnical Engineering and Geosciences, Civil Engineering School, Technical University of Catalonia, GHS, UPC, Barcelona, Spain.

Wagner, W., Pruss, A., 2002. The IAPWS formulation 1995 for the thermodynamic properties of ordinary water substance for general and scientific use.Journal of Physical and Chemical Reference Data 31 (2), 387-535. 
Xu, T., Ontoy, Y., Molling, P., Spycher, N., Parini, M., Pruess,K., 2004. Reactive transport modeling of injection well scaling and acidizing at Tiwi Field, Philippines. Geothermics 33(4), $477-491$.

Zeidouni, M., Pooladi-Darvish, M., Keith, D., 2009.Analytical solution to evaluate salt precipitation during $\mathrm{CO}_{2}$ injection in saline aquifers. International Journal of Greenhouse Gas Control 3, 600-611. 
Figure 1 - Gas $\left(\mathrm{k}_{\mathrm{rg}}\right)$ and water $\left(\mathrm{k}_{\mathrm{rl}}\right)$ relative permeability curves (left) and capillary pressure curve (right) for Vosges Sandstone samples (IFPEN Data)

Figure 2 - Experimental procedure to study the drying-out of a sandstone core under a continuous flux of anhydrous gas

Figure 3 - Molar fraction of water $\left(\mathrm{y}_{\mathrm{H} 2 \mathrm{O}}\right)$ in the gas phase at $80^{\circ} \mathrm{C}$ according to pressure.

Figure 4 - Mean water content in the core and outlet gas flux (at $80^{\circ} \mathrm{C}$ ): symbols are measured data and lines are calculated values

Figure 5 - Relationship between porosity and permeability reduction, fromVerma and Pruess(1988) optimized for Vosges Sandstone $\left(\Pi=0.8\right.$ and $\left.\phi_{r}=0.91\right)$ where $\Pi$ is the fractional length of pore bodies and $\phi_{r}$ is the fraction of initial porosity for which permeability is reduced to zero. $\mathrm{K}$ and $\phi$ are permeability and porosity at time $\mathrm{t}$, respectively, and subscript 0 indicates the initial values of these two rock parameters.

Figure 6 - Modelling results for the variations in permeability inside the core during $\mathrm{CO}_{2}$ injection, for gas injection with increasing pressure steps (solid grey line) and for a constant pressure gradient (dotted grey line).

Figure 7 - Comparison between measured X-ray adsorption (back line - Peysson et al., 2013) and the calculated amounts of salt deposits for gas injection by increasing pressuresteps (solid grey line) and for a constant pressure gradient (dotted grey line).

Figure 8 - Permeability variations around the injection well depending on brine salinity, for the same pressure gradient $(\Delta \mathrm{P}=2$ bars $)$. $\mathrm{k}$-red $\left(=\mathrm{K} / \mathrm{K}_{0}\right)$ is the permeability reduction according 
Figure 9-(a) Permeability variations close to the injection well as a function of the injection flow rate for three initial brine salinities (between 10 and $160 \mathrm{~g} / \mathrm{L}$ ); (b) Prediction of the risk of clogging close to the injection well depending on the injection flow rate and Peclet number

Figure 10 - (a)Gas Saturation (SG), (b) Solid Saturation (SS) (= precipitated salt volume/pore volume), and (c) permeability reduction ( $\mathrm{k}-\mathrm{red}=\mathrm{K} / \mathrm{K}_{0}$ ) withina $100 \mathrm{~m}$ radius around the injector after ten years of supercritical $\mathrm{CO}_{2}$ injection, where $\mathrm{K}_{0}$ is the initial permeability Figure 11 - Gas (a) and brine (b) fluxes withina 100 m radius around the injector after ten years of supercritical $\mathrm{CO}_{2}$ injection. The lengths of the flow vectors (drawn at the center of each grid cell) are proportional to the intensity of the flow. Arrows indicate flow direction.

Figure 12 - Conceptual model of the main fluxes inside a homogeneous reservoir during supercritical $\mathrm{CO}_{2}$ injection 


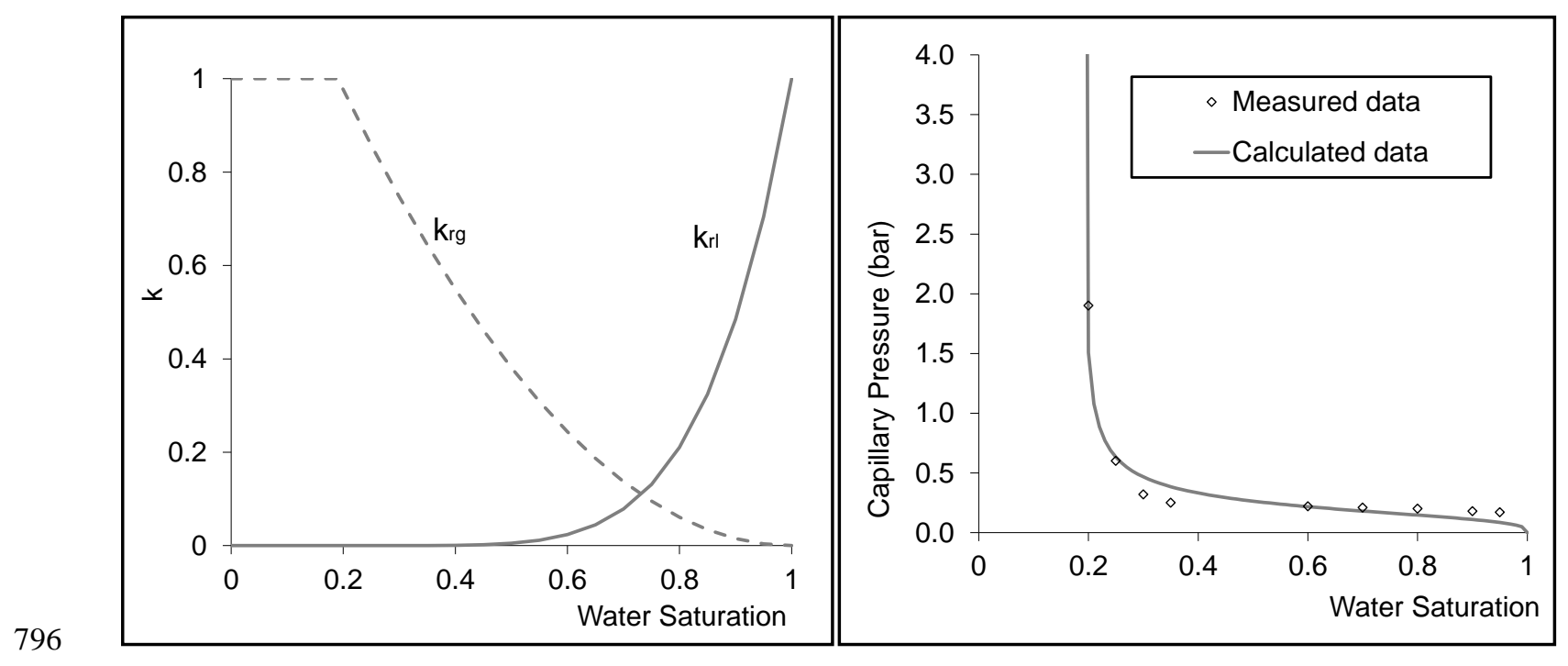

Figure 1 


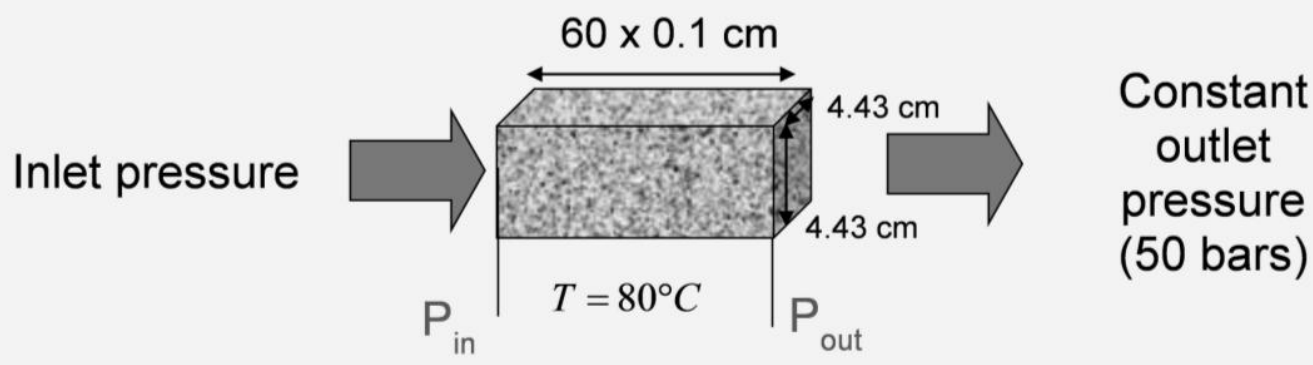

800

Figure 2

801 


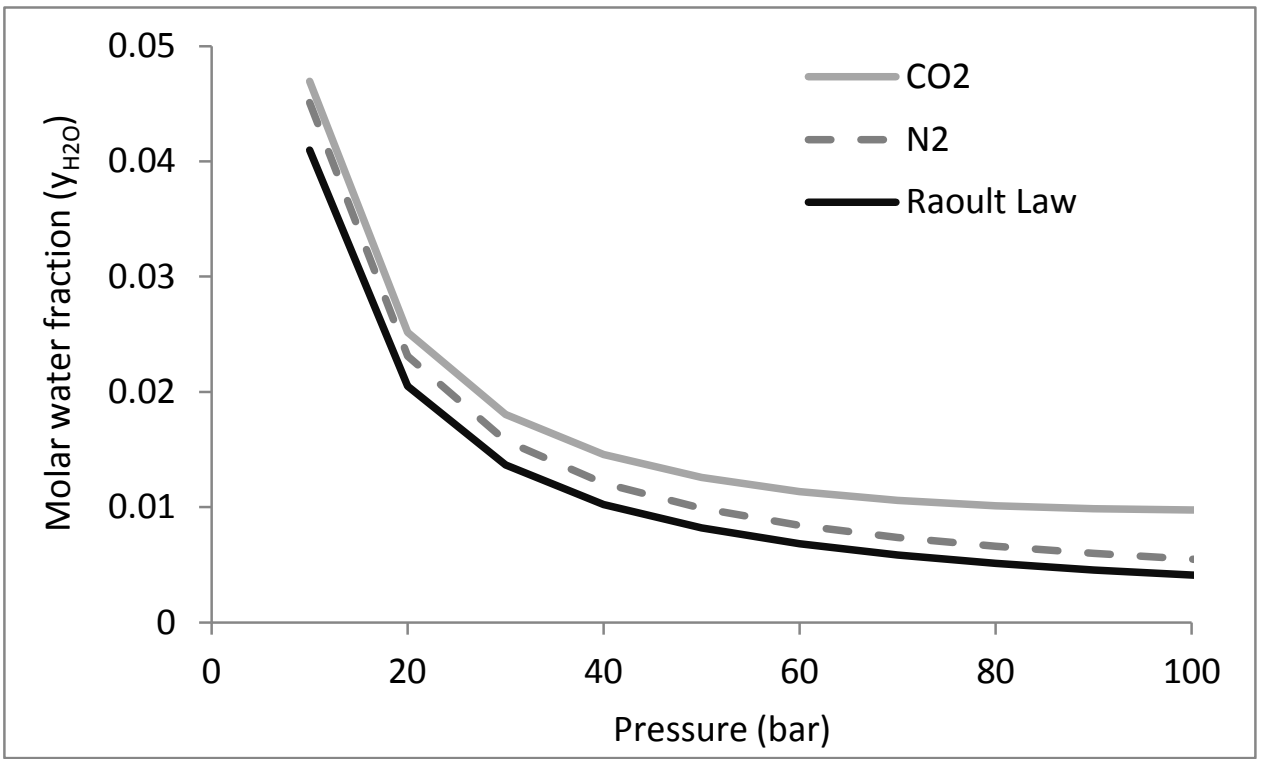

803

Figure 3 


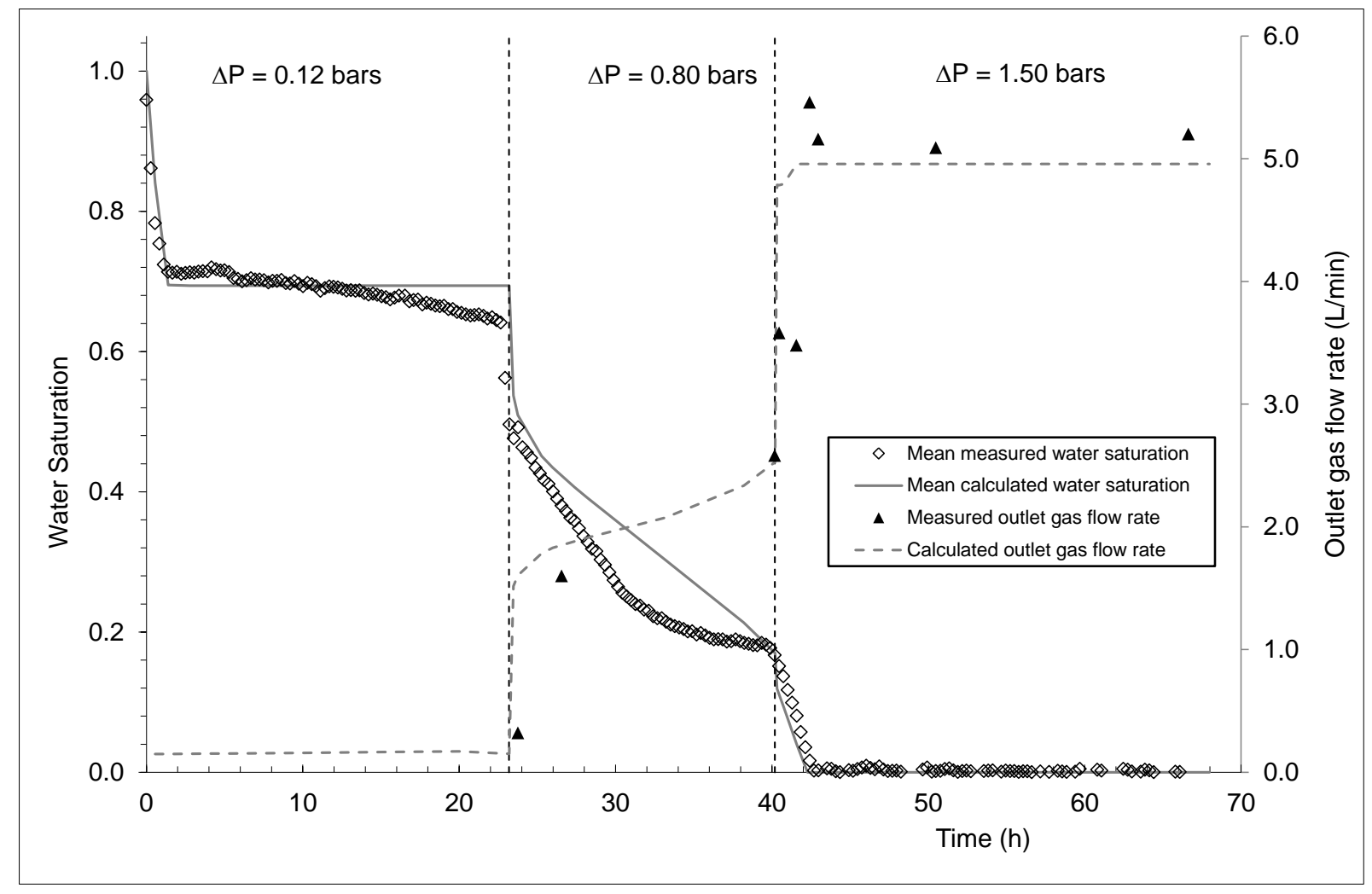

807

Figure 4 


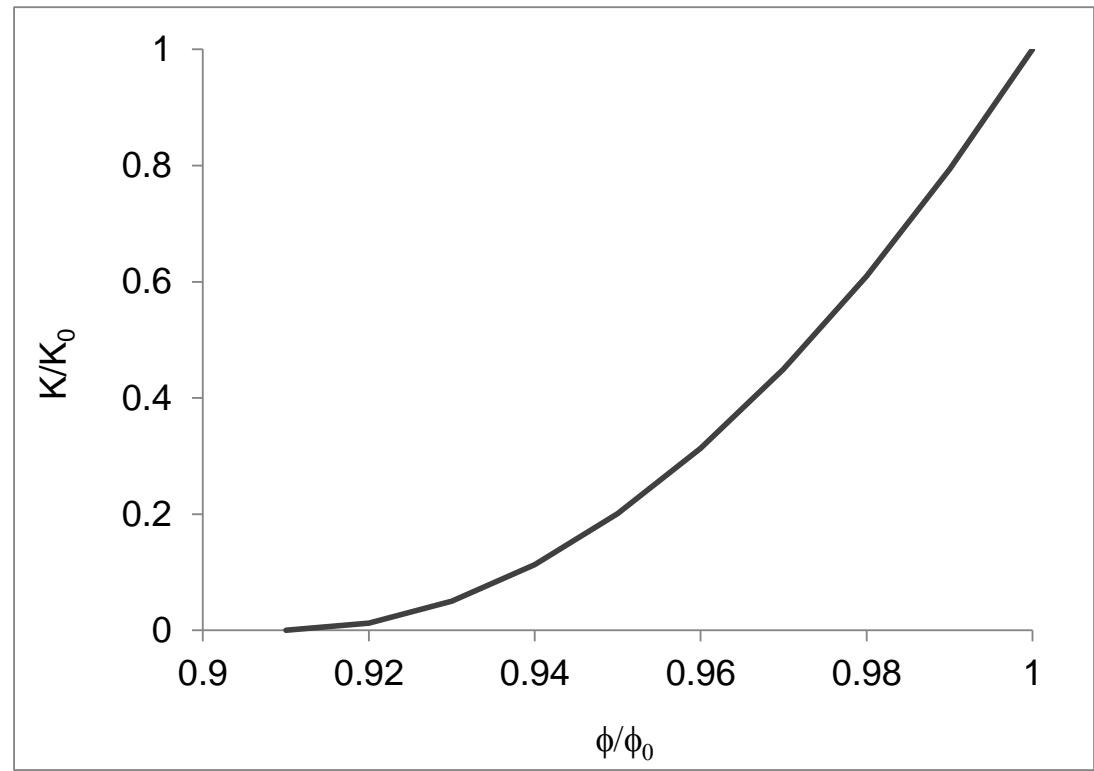

810

Figure 5

811 


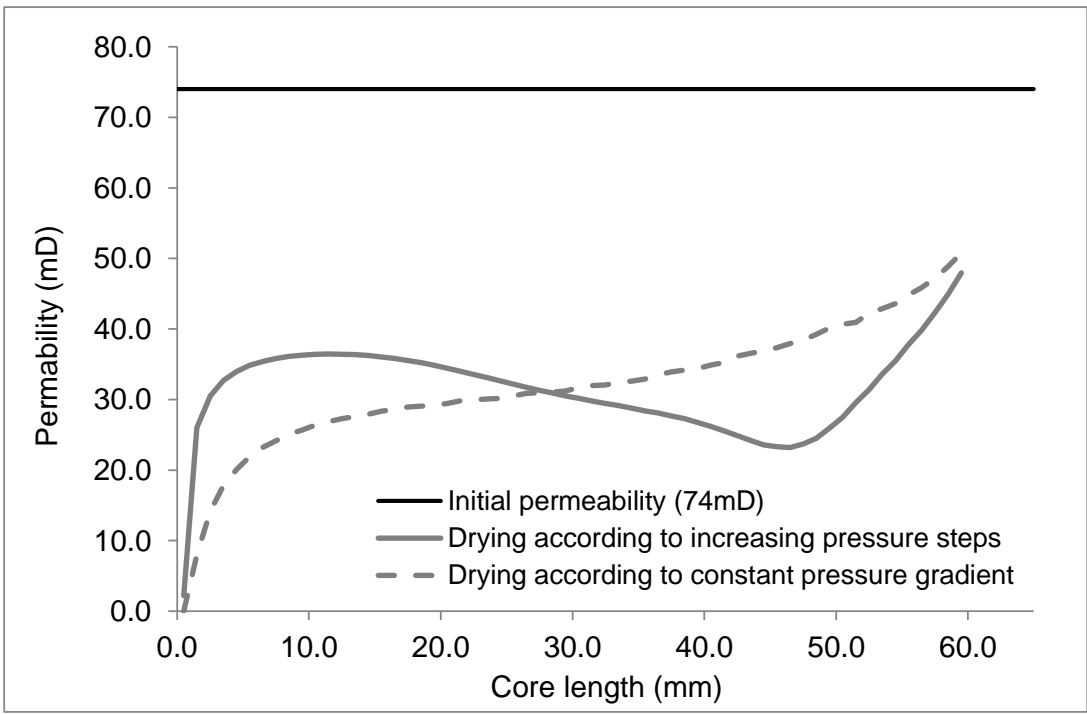




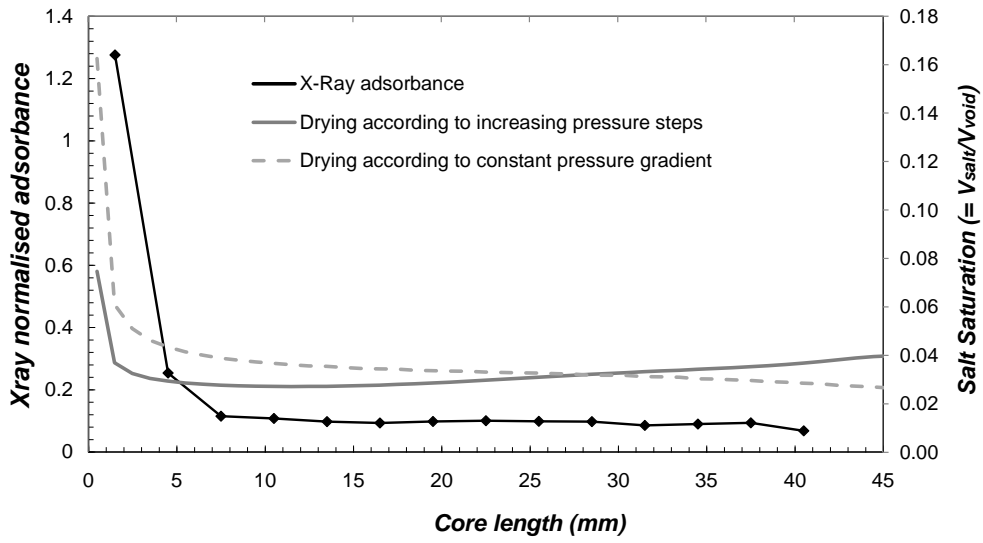




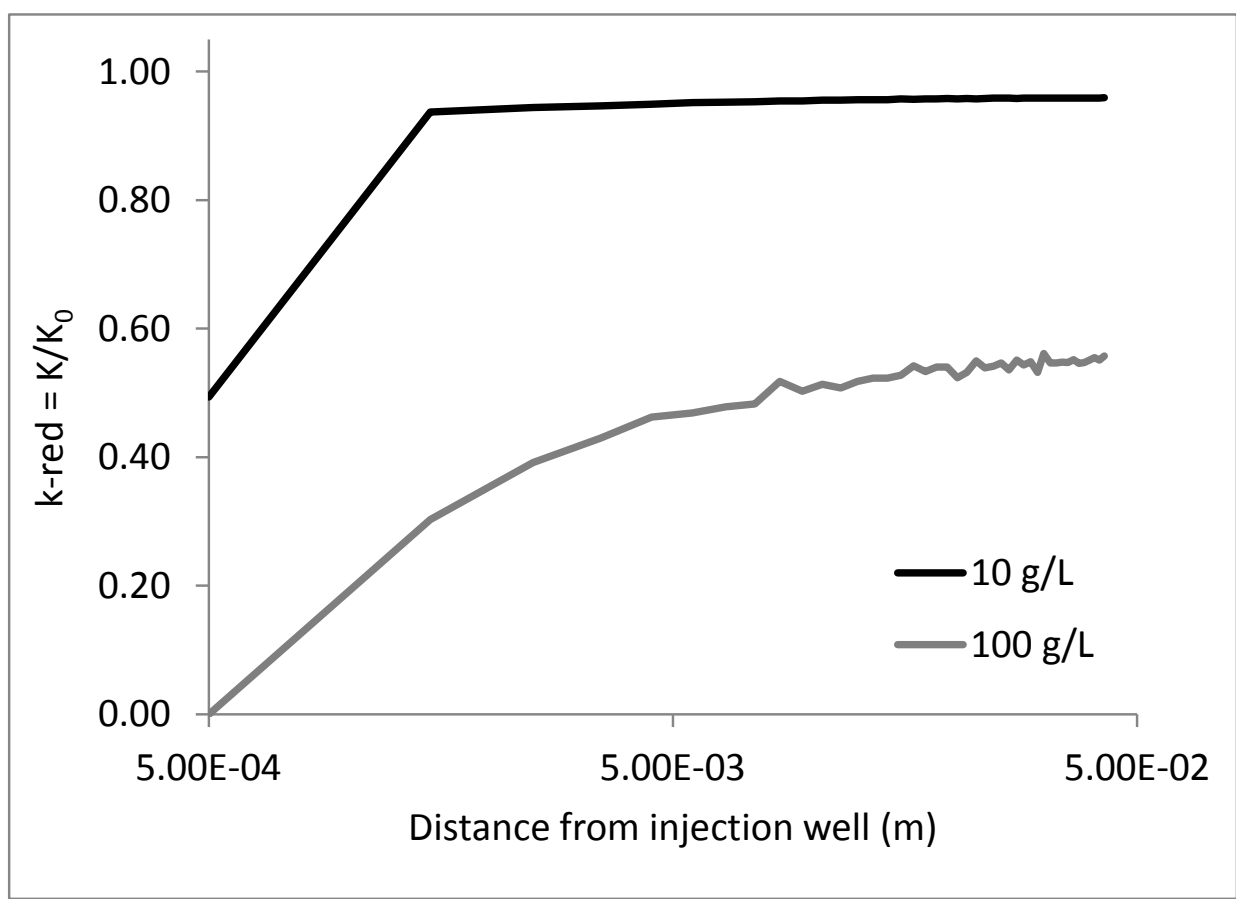

820

Figure 8 


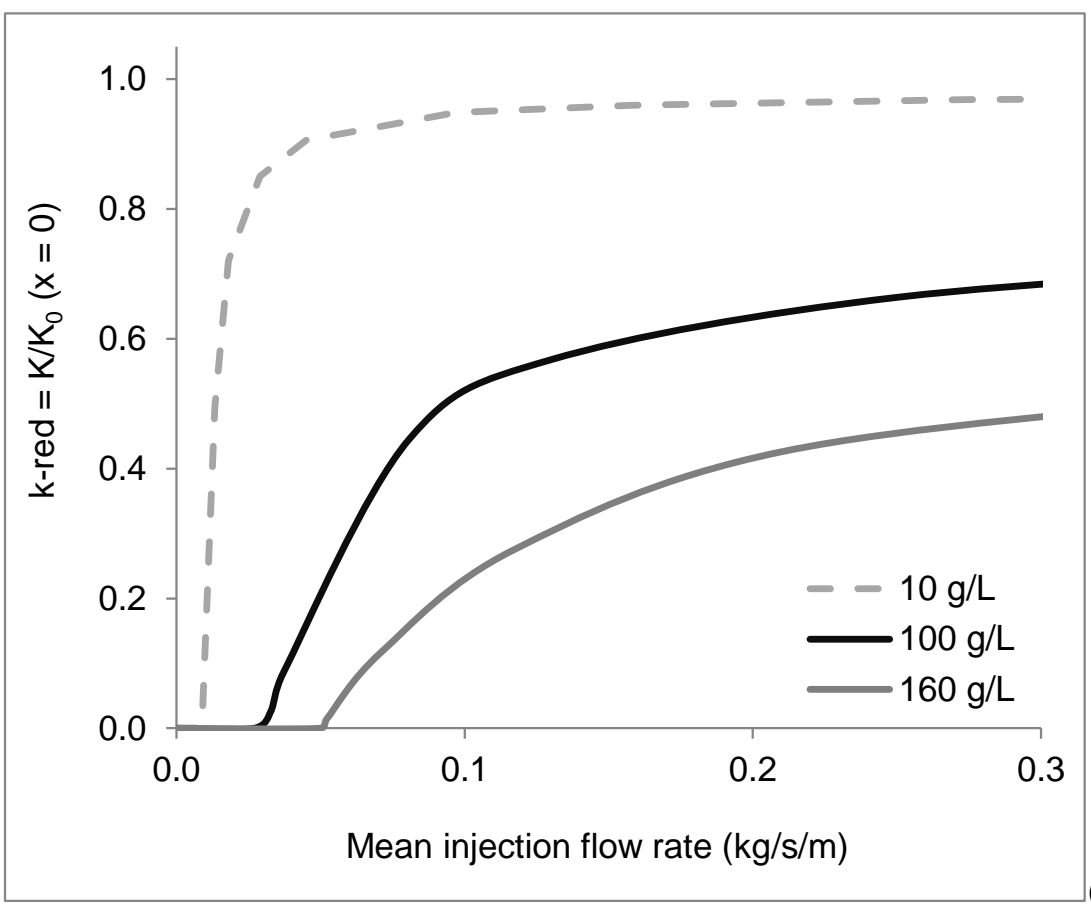

(a)

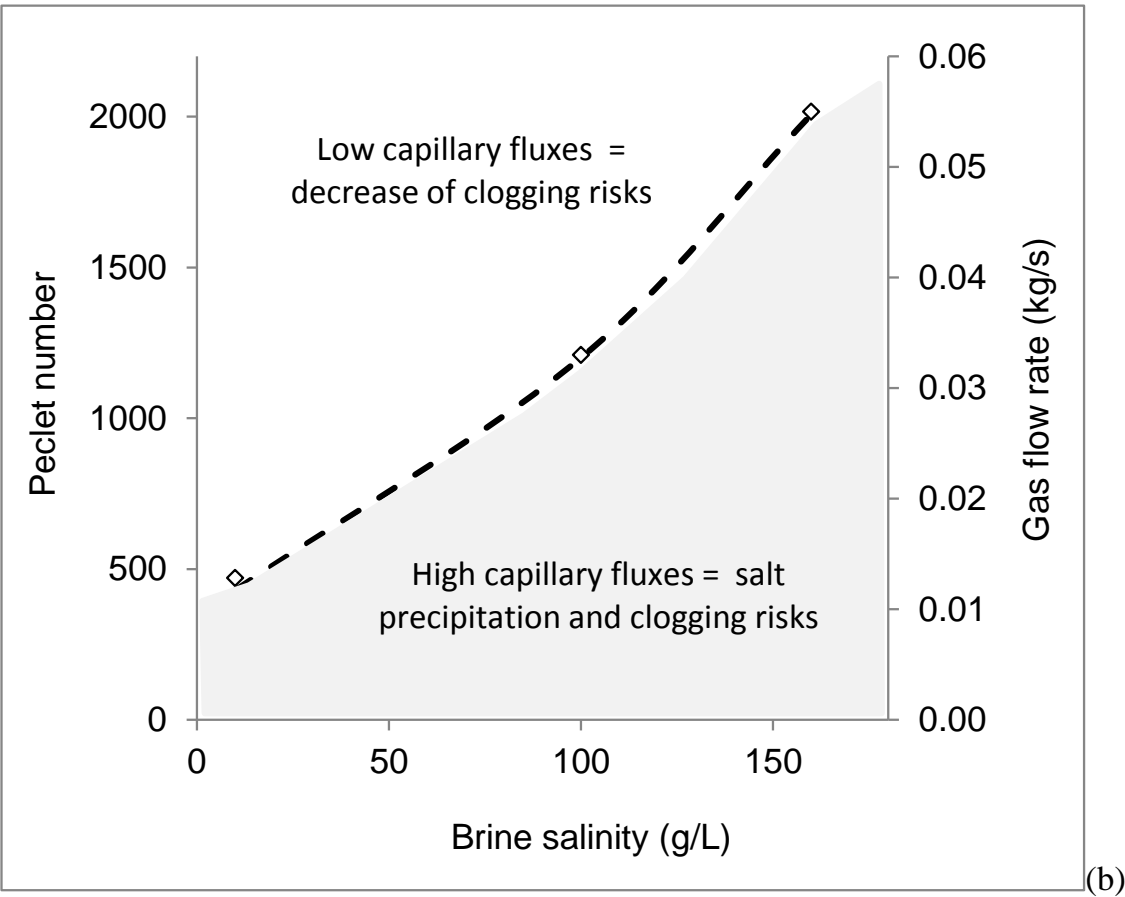


(b)

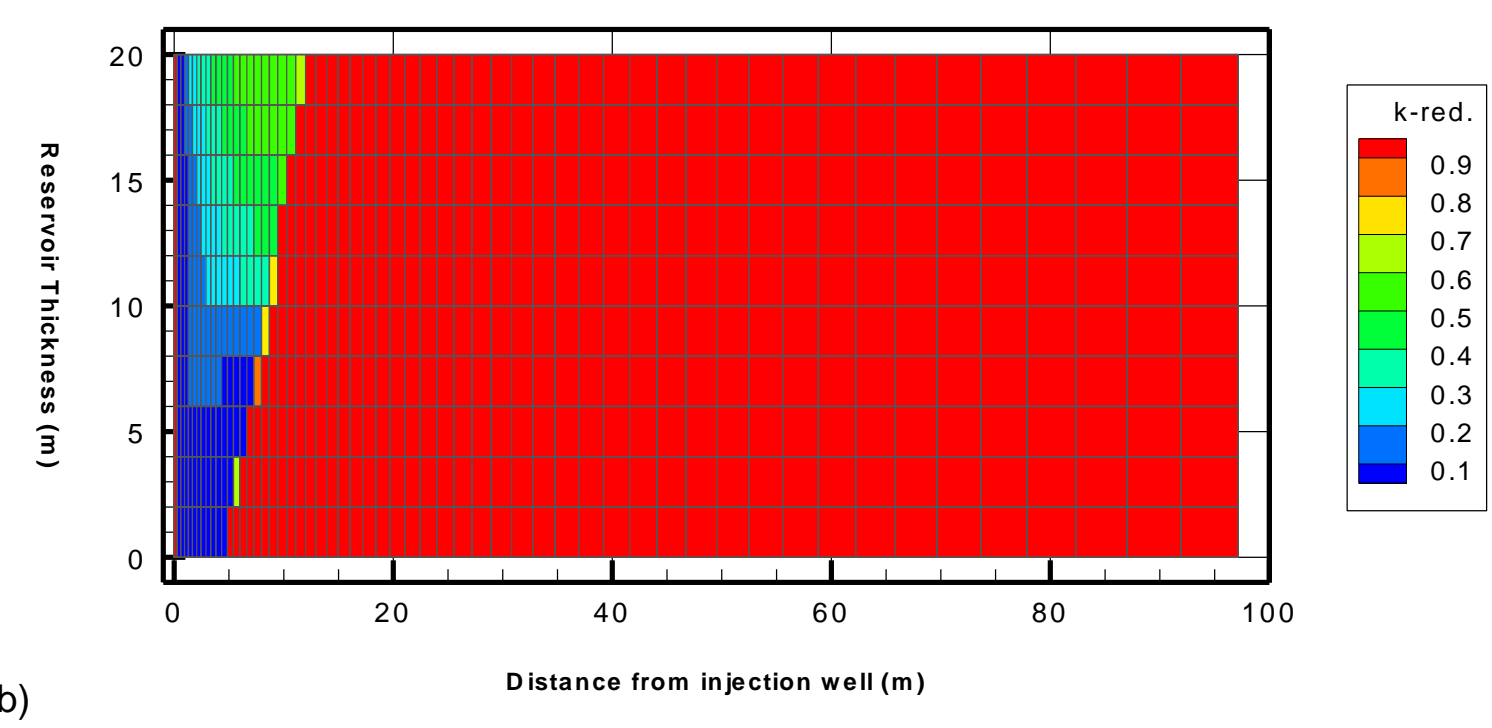

(a)
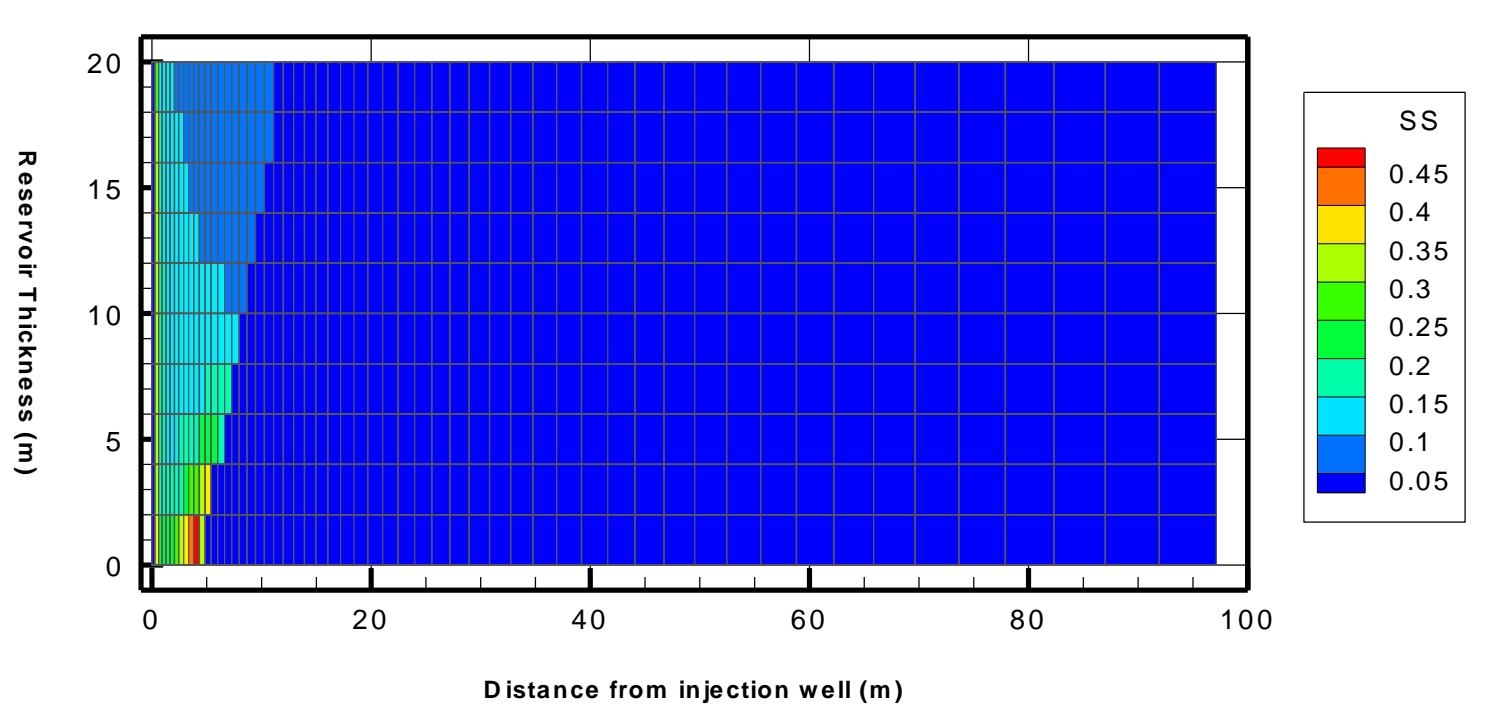





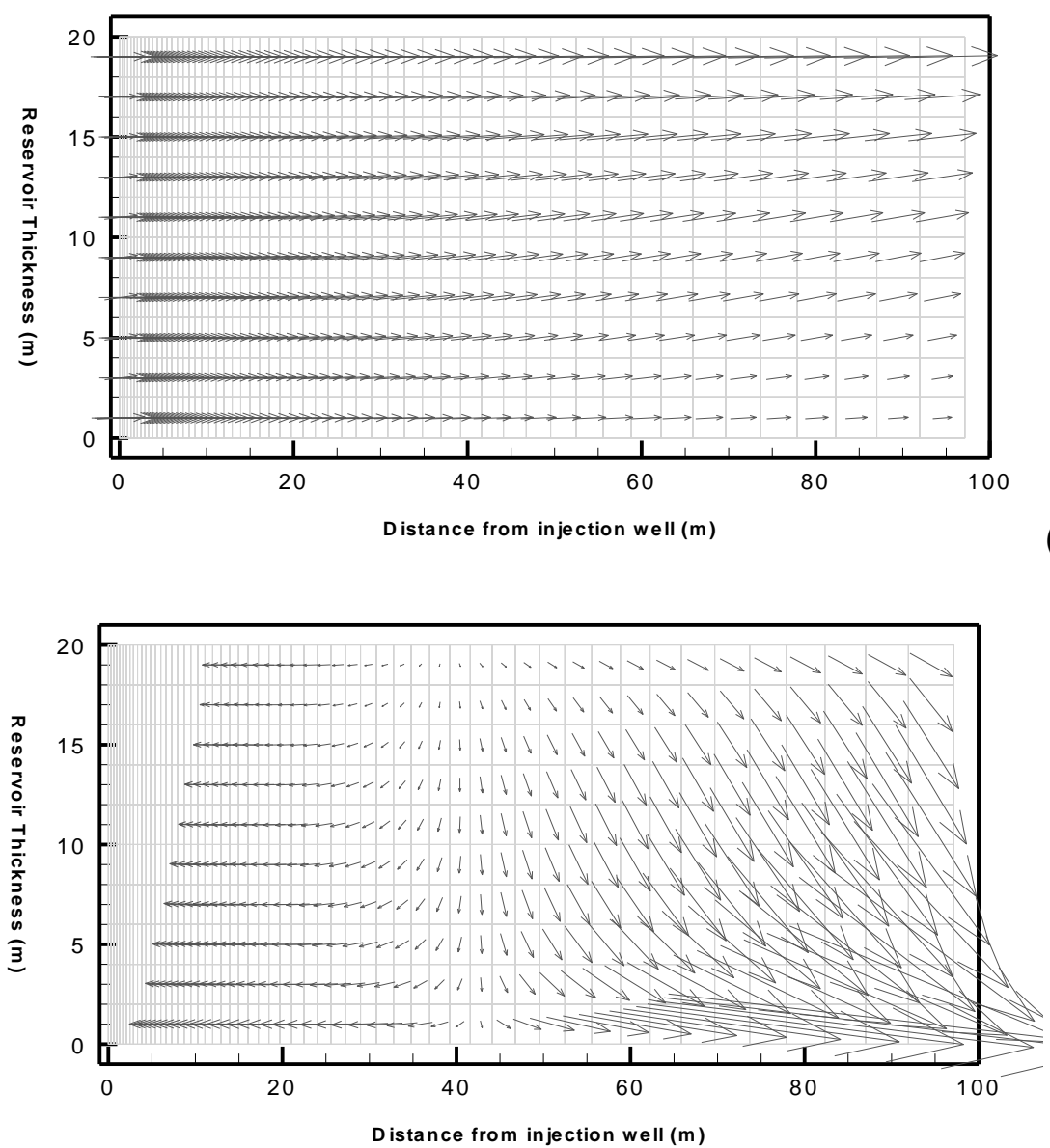




